\title{
Differential Regulation of Cone Calcium Signals by Different Horizontal Cell Feedback Mechanisms in the Mouse Retina
}

\author{
Robin Kemmler, ${ }^{1,2,3}$ Konrad Schultz, ${ }^{5}$ Karin Dedek, ${ }^{5,6}$ Thomas Euler, ${ }^{1,2,4}$ and Timm Schubert ${ }^{1,2}$ \\ ${ }^{1}$ Institute for Ophthalmic Research, Centre for Ophthalmology, ${ }^{2}$ Centre for Integrative Neuroscience, ${ }^{3}$ Graduate School of Cellular and Molecular \\ Neuroscience, and ${ }^{4}$ Bernstein Centre for Computational Neuroscience, University of Tübingen, 72076 Tübingen, Germany, ${ }^{5}$ Department of Neurobiology, \\ University of Oldenburg, 26111 Oldenburg, Germany, and ${ }^{6}$ Research Center Neurosensory Science, University of Oldenburg, 26111 Oldenburg, Germany
}

\begin{abstract}
Controlling neurotransmitter release by modulating the presynaptic calcium level is a key mechanism to ensure reliable signal transmission from one neuron to the next. In this study, we investigated how the glutamatergic output of cone photoreceptors (cones) in the mouse retina is shaped by different feedback mechanisms from postsynaptic GABAergic horizontal cells (HCs) using a combination of twophoton calcium imaging and pharmacology at the level of individual cone axon terminals. We provide evidence that hemichannelmediated (putative ephaptic) feedback sets the cone output gain by defining the basal calcium level, a mechanism that may be crucial for adapting cones to the ambient light level. In contrast, $\mathrm{pH}$-mediated feedback did not modulate the cone basal calcium level but affected the size and shape of light-evoked cone calcium signals in a contrast-dependent way: low-contrast light responses were amplified, whereas high-contrast light responses were reduced. Finally, we provide functional evidence that GABA shapes light-evoked calcium signals in cones. Because we could not localize ionotropic GABA receptors on cone axon terminals using electron microscopy, we suggest that GABA may act through GABA autoreceptors on HCs, thereby possibly modulating hemichannel- and/or pH-mediated feedback. Together, our results suggest that at the cone synapse, hemichannel-mediated (ephaptic) and pH-mediated feedback fulfill distinct functions to adjust the output of cones to changing ambient light levels and stimulus contrasts and that the efficacy of these feedback mechanisms is likely modulated by GABA release in the outer retina.
\end{abstract}

Key words: calcium; feedback inhibition; horizontal cells; photoreceptors; retina; transmitter release

\section{Introduction}

In neurons, transmitter release from axon terminals is directly linked to the $\mathrm{Ca}^{2+}$ level (Thoreson, 2007; Jackman et al., 2009). Thus, one key mechanism to control transmitter release is to modulate presynaptic $\mathrm{Ca}^{2+}$ by synaptic feedback (for review, see Kamermans and Fahrenfort, 2004). "Traditional” GABAergic feedback, but also more unconventional mechanisms like ephaptic and $\mathrm{pH}$-mediated feedback, are found in many parts of the CNS (for review, see Voronin, 2000; Chesler, 2003). However, little is known whether these mechanisms operate in parallel to control transmitter release forming a complex feedback system and, if so, to what extent they fulfill distinct functions.

An excellent system to study such feedback mechanisms is the photoreceptor synapse in the retina. Here, cone photoreceptors

Received Jan. 21, 2014; revised July 14, 2014; accepted July 17, 2014.

Author contributions: R.K., T.E., and T.S. designed research; R.K. and K.S. performed research; R.K., K.S., and T.E. analyzed data; R.K., K.S., K.D., T.E., and T.S. wrote the paper.

This work was supported by the Deutsche Forschungsgemeinschaft (EXC307, CIN to T.E. and T.S.; SCHU 2243/3-1 to T.S.; DE1154/3-1 to K.D.). We thank M. Kamermans and T. Baden for helpful discussions and for their comments on this manuscript, and M. Pottek for critical reading of this manuscript. We thank G. Eske for excellent technical assistance.

The authors declare no competing financial interests.

Correspondence should be addressed to Timm Schubert, CIN-Werner Reichardt Centre for Integrative Neuroscience, Institute for Ophthalmic Research, University of Tübingen, Otfried Müller Str. 25, 72076 Tübingen, Germany. E-mail: timm.schubert@cin.uni-tuebingen.de.

DOI:10.1523/JNEUROSCI.0272-14.2014

Copyright $\odot 2014$ the authors $\quad 0270-6474 / 14 / 3411826-18 \$ 15.00 / 0$ (cones) form synapses with the dendrites of horizontal cells (HCs) and bipolar cells (Haverkamp et al., 2000), distributing the photoreceptor output onto more than 10 parallel bipolar cell-toganglion cell pathways. Horizontal cells modulate cone output via both inhibitory (Baylor et al., 1971) and excitatory (Jackman et al., 2011) feedback. The inhibitory feedback operates on a global scale and adjusts cone output gain as a function of background illumination, as sensed by the electrically coupled HC network (Xin and Bloomfield, 1999). The excitatory feedback, on the other hand, is suggested to act locally and to restore the cone's dynamic range lost by inhibitory feedback (Jackman et al., 2011). Three different inhibitory feedback mechanisms between HCs and cones have been proposed based on data from a range of vertebrate species: GABA-mediated feedback (Wu, 1986; Tatsukawa et al., 2005), hemichannel-mediated ephaptic feedback (Kamermans et al., 2001; Klaassen et al., 2011), and pH-mediated feedback (Barnes et al., 1993; Hirasawa and Kaneko, 2003; Liu et al., 2013).

In the mouse retina, there is evidence that HCs may use more than one of these mechanisms: this includes experimental data in favor of GABAergic transmission (Cueva et al., 2002; Herrmann et al., 2011; Hirano et al., 2011), ephaptic feedback via Pannexin1-formed hemichannels (Kranz et al., 2013), and pHmediated feedback (Babai and Thoreson, 2009). Because mice possess only a single HC type (Peichl and Gonzalez-Soriano, 1994), the presence of multiple mechanisms in the mouse hints at 
A

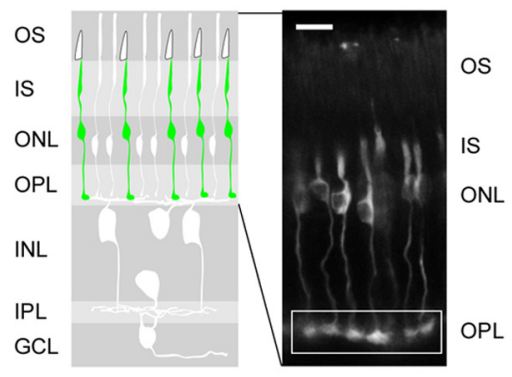

B

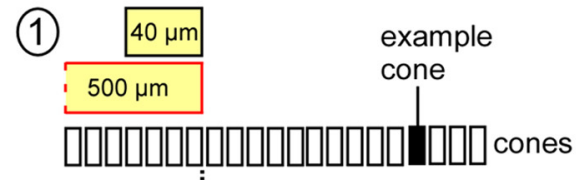

(2)

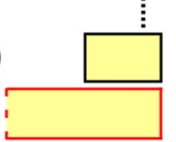

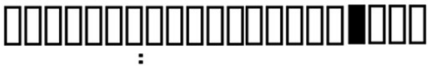

(3)

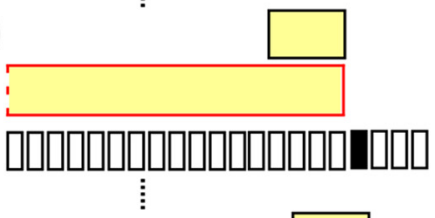

(4)

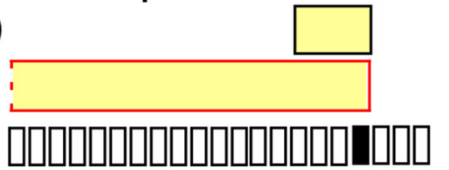

$\mathbf{F}$

H
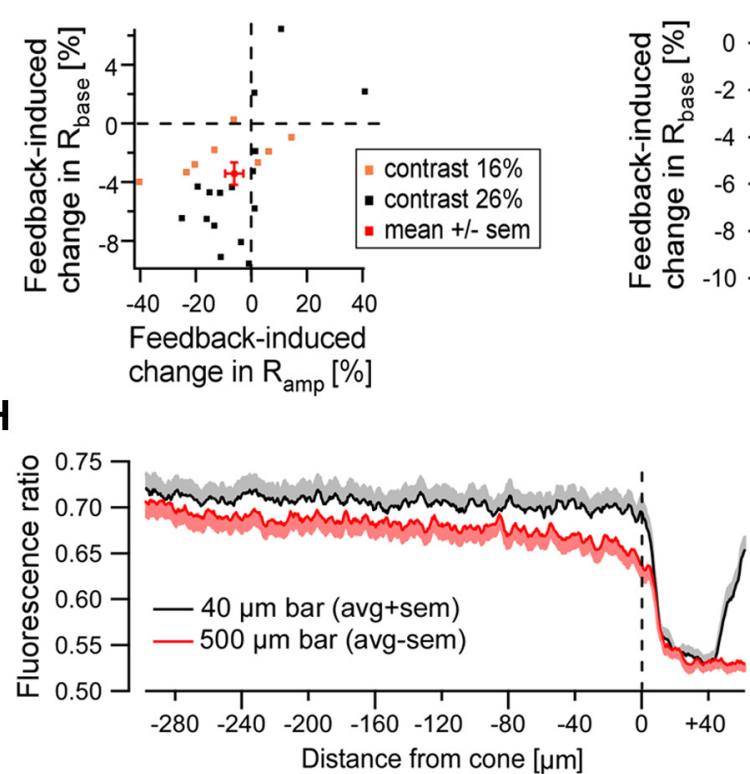

C

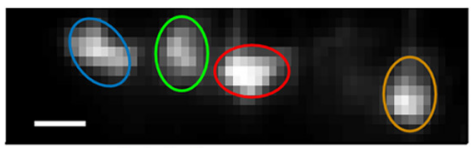

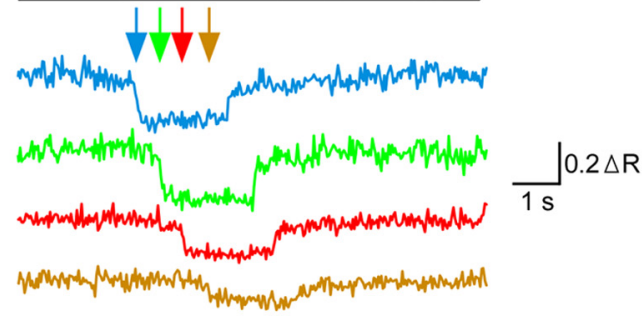

(1)(2) $\cdots$ (3)(4)

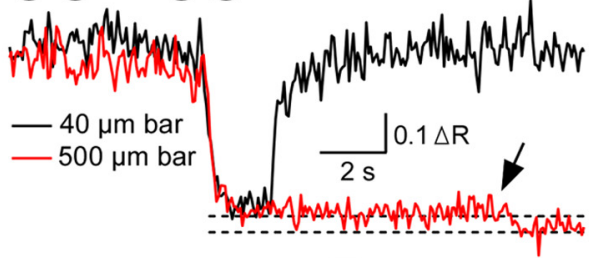

$E_{1}$

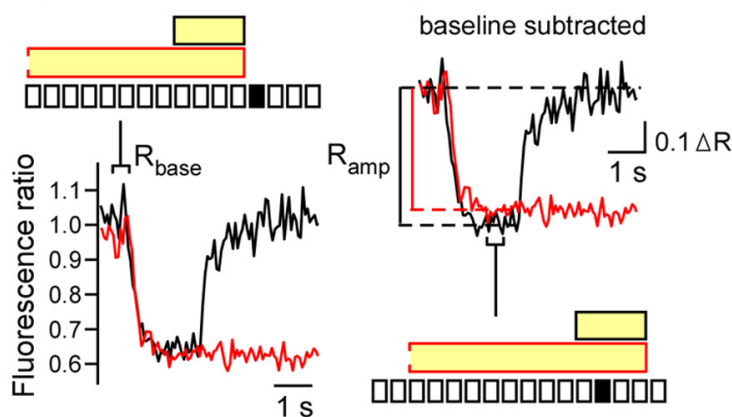

\section{G}

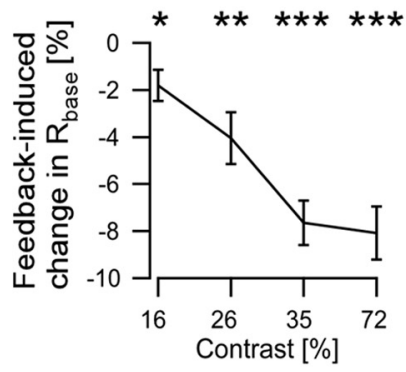

I

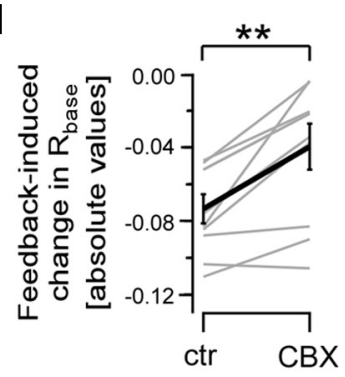

Figure 1. Bright stimulus in cone surround reduces $\mathrm{Ca}^{2+}$ level and relative response amplitude. $\boldsymbol{A}$, The $\mathrm{Ca}^{2+}$ indicator TN-XL (green) is selectively expressed in cone photoreceptors of the HR2.1:TN-XL mouse line (Wei et al., 2012). $\mathrm{Ca}^{2+}$ measurements were restricted to the cone terminals (box). OS, Outer segment; IS, inner segment; ONL, outer nuclear layer; INL, inner nuclear layer; IPL, inner plexiform layer; $G C L$, ganglion cell layer. Scale bar, $10 \mu \mathrm{m} . \boldsymbol{B}$, Illustration of stimulus paradigm: a small bright bar was shifted stepwise along a retinal slice (the row of boxes represents cones) toward the center of an exemplary cone (black box) by $10 \mu \mathrm{m}$ every $0.5 \mathrm{~s}$. The procedure was repeated with a large bright bar. C, $\mathrm{Ca}^{2+}$ responses of neighboring cone axon terminals (encircled by regions of interests at the top; scale bar, $5 \mu \mathrm{m}$ ) to the small bright bar (sequential onset of response indicated by the arrows). $\boldsymbol{D}, \mathrm{Ca}^{2+}$ response (as change in ratio between the fluorescence signals of the FRET donor/acceptor pair eCFP and citrine; average of $n=6$ trials) of the example cone (from $\boldsymbol{B}$ ) to the small (black trace) and large (red trace) bars; the numbers refer to the different stimulus phases as illustrated in $\boldsymbol{B}$. Initially, the bars were about $100 \mu \mathrm{m}$ distant from the exemplary cone (position 1); the decrease in $\mathrm{Ca}^{2+}$ indicates when the edge (Figure legend continues.) 
Table 1. Light stimulation protocols

\begin{tabular}{|c|c|c|c|c|}
\hline $\begin{array}{l}\text { Intensity } \\
\text { Protocol }\end{array}$ & $\begin{array}{l}\text { Background } \\
\text { laser }\left(10^{3}\right. \\
\left.\mathrm{P}^{*} \text { cone }^{-1} s^{-1}\right)\end{array}$ & $\begin{array}{l}\text { Background } \\
\operatorname{LED}\left(10^{3}\right. \\
\left.\mathrm{P}^{*} \text { cone }^{-1} \mathrm{~s}^{-1}\right)\end{array}$ & $\begin{array}{l}\text { Stimulus }\left(10^{3}\right. \\
\left.\mathrm{P}^{*} \text { cone }^{-1} \mathrm{~s}^{-1}\right)\end{array}$ & $\begin{array}{l}\text { Contrast } \\
(\%)\end{array}$ \\
\hline \multirow[t]{4}{*}{ (b) Surround (bright stimulus) } & $\sim 10$ & 0.14 & 1.8 & 16 \\
\hline & $\sim 10$ & 0.14 & 2.8 & 26 \\
\hline & $\sim 10$ & 0.14 & 3.7 & 35 \\
\hline & $\sim 10$ & 0.14 & 7.5 & 72 \\
\hline (c) Surround (dark stimulus) & $\sim 10$ & 7.5 & 0.14 & -71 \\
\hline (d) Receptive fields & $\sim 10$ & 7.5 & 0.14 & -71 \\
\hline (e) High bright contrast & $\sim 10$ & 1.3 & 12.0 & 95 \\
\hline (f) Medium bright/dark & $\sim 10$ & 4.6 & 12.0 & 51 \\
\hline contrast & $\sim 10$ & 4.6 & 1.3 & -23 \\
\hline (g) High dark contrast & $\sim 10$ & 8.6 & 1.3 & -39 \\
\hline
\end{tabular}

Light levels for the different stimulation protocols, measured as described in Materials and Methods.

a complex processing of cone input and feedback signals in this interneuron. It is unclear whether the hypothesized HC feedback mechanisms modulate different temporal and spatial aspects of the cone output and how they might interact in the mouse.

To address the question how HCs control synaptic $\mathrm{Ca}^{2+}$ in cone axon terminals, we combined two-photon microscopy and pharmacology to analyze the effects of $\mathrm{HC}$ feedback mechanisms on light-evoked cone synaptic output, with $\mathrm{Ca}^{2+}$ signals directly recorded at the level of the cone axon terminal as a proxy. We provide evidence for the presence of both hemichannel-mediated (putative ephaptic) and $\mathrm{pH}$-mediated feedback, each of them fulfilling distinct functions to adjust cone output to ambient light levels and changing stimulus contrasts, respectively. Moreover, we suggest that GABA modulates cone output indirectly possibly by acting on GABA receptors on HCs, thereby changing the efficacy of the other two feedback mechanisms.

\section{Materials and Methods}

Unless stated otherwise, all chemicals were purchased from SigmaAldrich and Merck.

Animals. For electron microscopy, light-adapted C57B6L/J mice (4-8 weeks, both genders) were used. For $\mathrm{Ca}^{2+}$ imaging experiments, we used dark-adapted (for at least $2 \mathrm{~h}$ ) mice of the transgenic HR2.1:TN-XL mouse line (4-8 weeks, both genders; Wei et al., 2012). Animals were anesthetized with isoflurane (Baxter) or $\mathrm{CO}_{2}$ and killed by cervical dislocation. All procedures were performed in accordance with the law on animal protection (Tierschutzgesetz) issued by the German Federal Gov-

\section{$\leftarrow$}

(Figure legend continued.) of the bar entered the receptive field center of the cone (position 4). The $\mathrm{Ca}^{2+}$ signal was not "floored" by the contrast used, as the $\mathrm{Ca}^{2+}$ level could be further reduced by further increasing the light intensity (arrow). Only cells that showed a reduction in $\mathrm{Ca}^{2+}$ level of $>5 \%$ in response to this test stimulus compared with the immediate pretest period (i.e., cells that were not saturated) were used for further analysis. $E_{1}$, The baseline signal $R_{\text {base }}$ was determined in a time window of $0.5 \mathrm{~s}$ before the response onset (see Materials and Methods). $\boldsymbol{E}_{2}$, The response amplitude $R_{\text {amp }}$ was determined for the duration of the small bar response after subtraction of $R_{\text {base. }} F$, Surround stimulation-induced effects on $R_{\text {base }}$ and $R_{\text {amp }}$ quantified as the difference between the large and the small bar stimulation conditions and visualized as a scatter plot $\left[\Delta R_{\text {base }}\right.$ as a function of $\Delta R_{\text {amp }}$; average (red marker) pooled from low-contrast data only $[n=8(16 \%)$ and $n=16(26 \%)]$. G, Surround stimulation-induced reduction of $R_{\text {base }}$ as function of stimulus contrast $[n=14(16 \%), n=16(26 \%), n=11(35 \%)$, and $n=23(72 \%)]$. $\boldsymbol{H}$, Surround stimulation-induced effects on cone $\mathrm{Ca}^{2+}$ level as a function of distance from cone $(72 \%$ stimulus contrast; box-filtered average traces with a box width of $160 \mathrm{~ms} ; n=10$ cones; only cones $\geq 300 \mu \mathrm{m}$ away from stimulus starting were used). A distance of zero means that the leading edge of the stimulus bars is positioned at the cone's receptive field border (dashed line). $I$, Effect of CBX on surround stimulation-induced reduction of $R_{\text {base }}\left(n=10\right.$; for this analysis, only cones that showed a feedback-induced reduction in $R_{\text {base }}$ $>5 \%$ were used). Note that absolute ratio values are shown (same units as in $\boldsymbol{E}_{1}$ ). Error bars indicate SEM. ctr, Control. ernment and approved by the institutional committees on animal experimentation of the University of Tübingen and the University of Oldenburg.

Immunoelectron microscopy. Immunoelectron microscopy was performed as described by Janssen-Bienhold et al. (2001). Retinas were fixed for $40 \mathrm{~min}$ in $3 \%$ paraformaldehyde in $0.1 \mathrm{M}$ phosphate buffer $(\mathrm{PB}), \mathrm{pH}$ 7.4. After rinsing and cryoprotection ( $30 \%$ sucrose in $\mathrm{PB}$ overnight), tangential sections $(60 \mu \mathrm{m})$ were cut on a cryotome (Bright Instrument). Unspecific binding was blocked with $10 \%$ normal goat serum in PB for $2 \mathrm{~h}$, followed by incubation with the primary polyclonal antibodies directed against the $\mathrm{GABA}_{\mathrm{A}}$ receptor subunit $\alpha 1$ (1:400 in PB; SYnaptic SYstems) and the $\mathrm{GABA}_{C}$ receptor subunit $\rho$ (1:250 in PB; provided by $\mathrm{R}$. Enz and S. Haverkamp, MPI for Brain Research, Frankfurt, Germany) for $4 \mathrm{~d}$ at $4^{\circ} \mathrm{C}$. After several washes in $\mathrm{PB}$, sections were incubated with biotinylated goat anti-guinea pig IgG (1:250 in PB) and biotinylated goat anti-rabbit $\operatorname{IgG}(1: 250$ in $\mathrm{PB})$, respectively, overnight at $4^{\circ} \mathrm{C}$. Binding sites were detected by the Vectastain Elite ABC kit (Vector Laboratories). Sections were postfixed (2.5\% glutaraldehyde, $1 \%$ paraformaldehyde, $1 \mathrm{~h}$ ) and subjected to silver intensification, followed by an additional fixation with $1 \% \mathrm{OsO}_{4}$ in $\mathrm{PB}$ for $1 \mathrm{~h}$. Sections were dehydrated by increasing acetone concentrations (50-100\%) before being embedded in Agar 100 resin (Agar Scientific). Ultrathin sections were collected on copper grids and were photographed and analyzed with a Zeiss 902 electron microscope. Intensity and contrast were adjusted using Adobe Photoshop CS6 extended.

Retinal tissue preparation. Eyes were enucleated; placed in an extracellular solution that contained (in $\mathrm{mm}$ ) $125 \mathrm{NaCl}, 2.5 \mathrm{KCl}, 2 \mathrm{CaCl}_{2}, 1$ $\mathrm{MgCl}_{2}, 1.25 \mathrm{NaH}_{2} \mathrm{PO}_{4}, 26 \mathrm{NaHCO}_{3}, 0.5$ L-glutamine, and 20 glucose; and maintained at $\mathrm{pH} 7.4$ using carboxygen $\left(95 \% \mathrm{CO}_{2} / 5 \% \mathrm{O}_{2}\right)$. To ensure that a potential GABAergic feedback mechanism from HCs to cones remained functional in vitro, $150 \mu \mathrm{M}$ pyridoxal 5-phosphate, a cofactor of the glutamic acid decarboxylase, was added (Deniz et al., 2011). After removing cornea and lens, the retina was isolated from the eye-cup. Retinal slice preparation has been described in detail previously (Eggers and Lukasiewicz, 2006). In brief, retinas were dissected from the eye-cup, cut in half, and put onto filter paper $(0.22 \mu \mathrm{m}$ pore size; Millipore $)$ with the photoreceptor layer facing up. Vertical retinal slices of $300 \mu \mathrm{m}$ thickness were cut using a standard technique with a manual retina slicer (Werblin, 1978). Slices attached to the filter paper were stored in a carboxygenated extracellular solution in darkness at room temperature and transferred individually to the recording chamber. The slice in the recording chamber was constantly perfused with the carboxygenated extracellular solution at $36^{\circ} \mathrm{C}$.

Imaging light-evoked $\mathrm{Ca}^{2+}$ activity using two-photon microscopy. For $\mathrm{Ca}^{2+}$ imaging, we used a biosensor mouse line in which cones selectively express the fluorescence calcium sensor TN-XL, allowing measurements of light-evoked $\mathrm{Ca}^{2+}$ signals in cone axon terminals (Wei et al., 2012; Fig. $1 A, C)$. TN-XL consists of the $\mathrm{Ca}^{2+}$ sensor Troponin $\mathrm{C}$, flanked by the donor fluorophore enhanced $\mathrm{CFP}(\mathrm{eCFP})$ and the acceptor fluorophore citrine, and allows for ratiometric $\mathrm{Ca}^{2+}$ measurements (Mank et al., 2006). Measurements were made with a custom-built two-photon (2P) microscope (Denk et al., 1990) as described previously (Euler et al., 2009; Breuninger et al., 2011). In brief, the system was equipped with a modelocked Ti:sapphire laser (MaiTai-HP DeepSee; Newport SpectraPhysics) tuned to $860 \mathrm{~nm}$, two detection channels for fluorescence imaging of eCFP (483 bandpass (BP) 32; AHF, Analysentechnik) and citrine (535 BP 50; AHF), and a $20 \times$ water-immersion objective (XLUMPlanFL, $0.95 \mathrm{NA}$; Olympus). Image acquisition was performed using custom software [CfNT by M. Müller, MPI for Medical Research, Heidelberg, Germany; or ScanM by M. Müller and T. Euler running under IgorPro 6.3 (Wavemetrics)] restricted to the row of cone pedicles in the outer plexiform layer (OPL). This way, bleaching of the lightsensitive cone outer segments by the scanning laser could be essentially avoided (for details, see Wei et al., 2012; Baden et al., 2013b).

Light stimulators. Dichromatic light stimuli were generated by two stimulators. The first stimulator consisted of a reflective liquid-crystal display (LCoS-type; i-glasses; EST), coupled in the microscope's optical path. This LCoS-display was alternately illuminated by two bandpassfiltered (blue, $400 \mathrm{BP} 10$; green, $578 \mathrm{BP} 10$; AHF) LEDs to project spatio- 
A

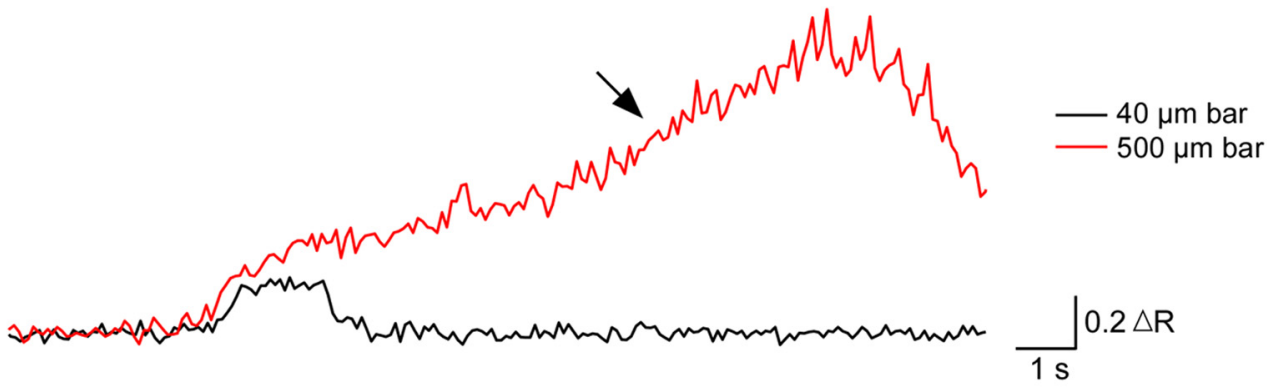

$B_{1}$

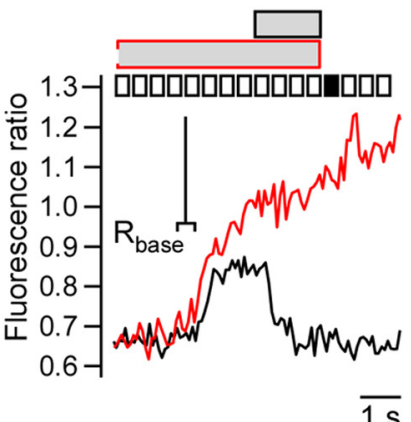

$\overline{1 \mathrm{~s}}$

D

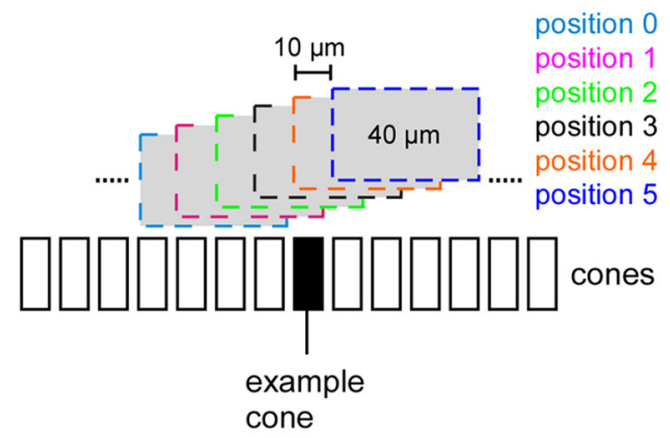

F

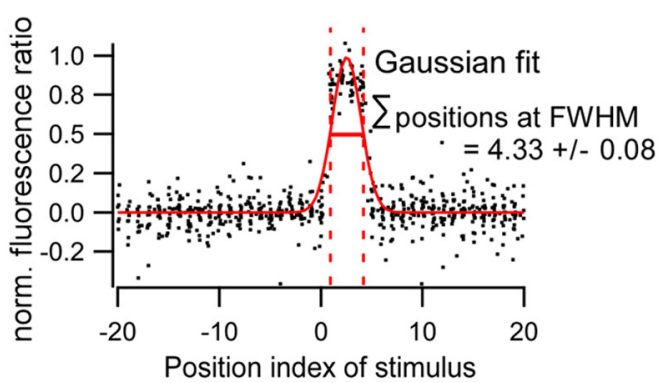

C

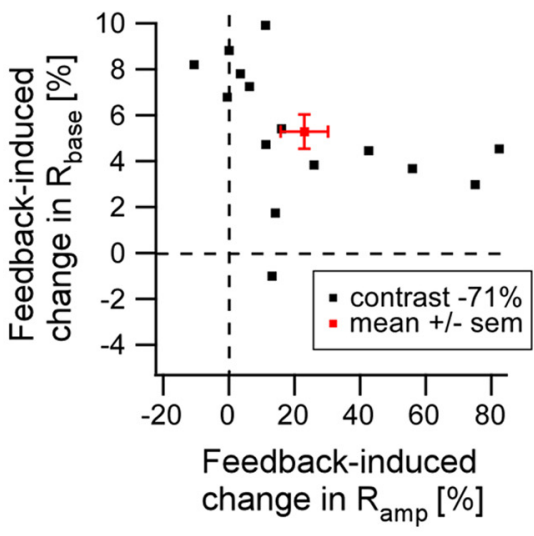

E

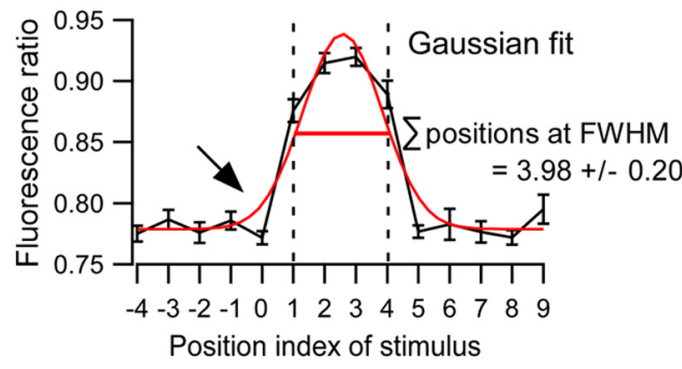

G

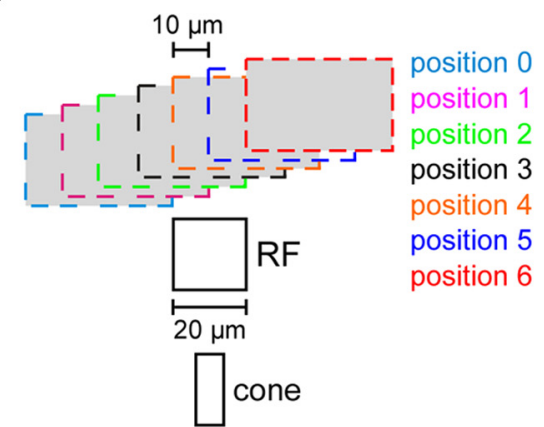

$\sum$ positions at FWHM (if $\mathrm{RF} \geq 20 \mu \mathrm{m}$ ) $>5.0$

Figure 2. Dark stimulus in cone surround increases $\mathrm{Ca}^{2+}$ level and relative response amplitude. $A, \mathrm{Ca}^{2+}$ responses of exemplary cone to a small (black trace) and a large (red trace) dark bar. Except for the inversed contrast, the stimulus paradigm is as shown in Figure 1B. Note that $\mathrm{Ca}^{2+}$ started to "ramp up" during the prolonged presentation of the large dark bar (arrow). This effect was reversible and seen in the majority of cones; the underlying mechanism remains to be determined. $\boldsymbol{B}, R_{\text {base }}$ and $R_{\text {amp }}$ were determined analogs to Figure $1 E$. C, Surround stimulation-induced effects on $R_{\text {base }}$ and $R_{\text {amp }}$ quantified and visualized analogs to Figure $1 F(n=15)$. D, Illustration of stimulus paradigm to probe the cone receptive field: a small dark bar ( $40 \mu \mathrm{m}$ wide) was pseudo-randomly presented at different positions (offset between two neighboring positions, $10 \mu \mathrm{m}$ ). At positions 1-4, the stimulus reaches into or covers the receptive field center of the exemplary cone (black box), whereas at positions 0 and 5 , the stimulus is outside its receptive field. $\boldsymbol{E}$, Average $\mathrm{Ca}^{2+}$ level of an individual cone as a function of stimulus position. Note the steep increase in $\mathrm{Ca}^{2+}$ level $($ between positions 0 and 1, see arrow; Gaussian fit in red). $\boldsymbol{F}$, Data from $n=17$ cones fitted with a Gaussian (red). $\mathbf{G}$, Estimating the number of stimulus positions that excite a cone with a certain receptive field diameter: for a $20 \mu \mathrm{m}$ RF, five subsequent stimulus positions are expected to trigger a cone response. Because cones responded to $4.33 \pm 0.08$ subsequent positions $(\boldsymbol{F})$, the RF diameter of mouse cones is $<20 \mu \mathrm{m}$ under our experimental conditions. Error bars indicate SEM. FWHM, Full-width half-maximum. 
temporally structured stimuli through the objective lens onto the retinal slice (Euler et al., 2009). This stimulator was used for the surround illumination experiments [see stimulus protocols (b) and (c) below]. The second stimulator was mounted below the recording chamber and consisted of two bandpassfiltered (UV, 360 BP 12; green, 578 BP 10; AHF) LEDs, driven by an open-source microprocessor board (http://arduino.cc) and synchronized with the microscope's galvo scanners. The light from the LEDs was combined by a beam-splitter (400 DCLP, AHF) and focused by a condenser lens (0.8 NA, H DIC; Zeiss) through the bottom of the recording chamber. This stimulator was used to apply full-field stimuli.

The light intensity generated by each of the stimulating LEDs was calibrated as described previously (Breuninger et al., 2011; Baden et al., 2013b; Chang et al., 2013) such that equal photoisomerization rates were elicited for short (S) and medium (M) wavelengthsensitive cone opsins. Cones were adapted to different background light levels for at least $20 \mathrm{~s}$ before stimuli were presented (see protocols below). The background intensity of the LEDs ranged from $0.14 \times 10^{3}$ to $7.5 \times 10^{3}$ $\mathrm{P}^{*}$ cone ${ }^{-1} \mathrm{~s}^{-1}$ for the first stimulator and from $1.3 \times 10^{3}$ to $8.6 \times 10^{3} \mathrm{P}^{*}$ cone $\mathrm{e}^{-1} \mathrm{~s}^{-1}$ for the second one (Table 1). Because both the light of the stimulator LEDs and the excitation laser contributed to the background light level at the slices, the laser was already scanning during this adaptation period. The contribution of the excitation laser to the background illumination was estimated to be $\sim 10^{4} \mathrm{P}^{*}$ cone ${ }^{-1} \mathrm{~s}^{-1}$, based on the transient $\mathrm{Ca}^{2+}$ response to laser and stimulator background at the beginning of a recording epoch (Wei et al., 2012). For a detailed discussion of potential laser-related stimulus contribution when recording retinal slices, see Baden et al. (2013b). The resulting illumination levels at the slices corresponded to high-mesopic/low-photopic conditions.

Light stimulation protocols. For light stimulation, eight different protocols were used:

(a) A "color protocol" consisting of alternating UV and green sine wave stimuli. This protocol was presented at the beginning of each recording session to determine the spectral preference of the cones (Baden et al., 2013b).

(b) A "stepping bar protocol" consisting of two alternating stimuli: a small (40 $\mu \mathrm{m}$ wide) and a large ( $500 \mu \mathrm{m}$ wide) bar, both brighter than the background light level. First, the small bar was consecutively shifted along the slice (in $10 \mu \mathrm{m}$ steps at $0.5 \mathrm{~s}$ intervals), starting at a position that was at least $200 \mu \mathrm{m}$ away from the position of the recorded cones (Fig. 1B). Then the procedure was repeated with the large bar (using the same starting position as for the small bar). The contrasts used were 16, 26, 35, and 72\% (all contrasts given as Weber contrast).

(c) Same protocol as in (b) but with bars darker than the background light level (Fig. 2). For technical reasons, we used only the green LED channel, and therefore this protocol was only tested for dorsal (dominantly $\mathrm{M}$ opsin-expressing) cones. The contrast used was $-71 \%$.

(d) A "receptive field measurement protocol" as a modification of the protocol in (c). A dark bar (40 $\mu \mathrm{m}$ wide) was pseudo-randomly presented at 61 different positions in a retinal slice (Fig. 2D). Since the distance between two neighboring positions was $10 \mu \mathrm{m}$, the lateral distance tested to each side of a recorded cone was about $300 \mu \mathrm{m}$.

For the pharmacology experiments, four different full-field flash protocols were used (Fig. 3). Full field means that the stimulus diameter was $\sim 2 \mathrm{~mm}$ and, therefore, usually covered the whole slice.
B
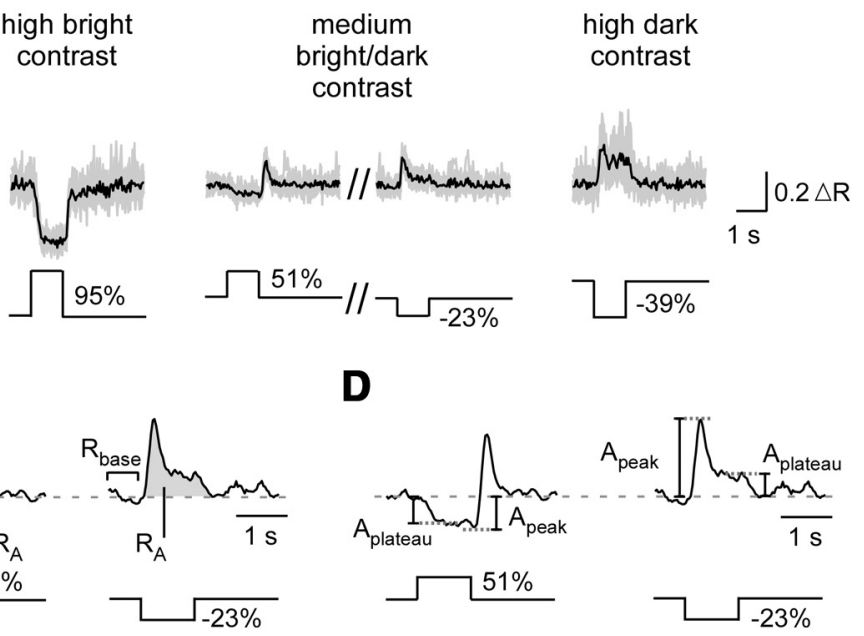

(e) The "high bright-contrast protocol" included stimulation with bright flashes ( $95 \%$ contrast).

(f) The "medium bright-/dark-contrast protocol" included alternating stimulation with dark flashes $(-23 \%$ contrast $)$ and bright flashes (51\% contrast).

(g) The "high dark-contrast protocol" included stimulation with dark flashes ( $-39 \%$ contrast).

(h) A saw-tooth ("intensity ramp") stimulus that covered the whole intensity range as in $(\mathrm{e}-\mathrm{g})$.

Pharmacology and drug application. Drugs were bath applied for at least $5 \mathrm{~min}$ and washed out for at least $10 \mathrm{~min}$. The volume of the recording chamber was $\sim 1 \mathrm{ml}$, and the perfusion rate was $\sim 2 \mathrm{ml} / \mathrm{min}$. In some experiments, drugs were puff applied onto the recorded photoreceptor axon terminal region (distance from recorded region, 15-20 $\mu \mathrm{m}$ ) for $20-60 \mathrm{~s}$ using a glass pipette (resistance, $5-8 \mathrm{M} \Omega$ ) and a pressure application system (Sigmann Elektronik; pressure, $0.3-1.0$ bar). By adding the fluorescent dye sulforhodamine 101 (Sigma-Aldrich), we verified that the puffing area on the tissue did not exceed a lateral width of $\sim 100 \mu \mathrm{m}$ and estimated (using the decrease in sulforhodamine fluorescence) that the effective concentration of puff-applied drugs is at least four times lower in the tissue than in the pipette. Puffing extracellular solution had no effect on cone $\mathrm{Ca}^{2+}$ signals.

The following drug concentrations were used for bath application (in

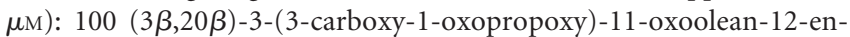
29-oic acid disodium (carbenoxolone; $\mathrm{CBX}$ ), $100 \mathrm{CoCl}_{2}$ hexahydrate, 0.2 PD168077 maleate, 100 meclofenamic acid sodium salt (MFA), 500 probenecid (PBC), 20,000 HEPES, 10 gabazine [Gz; 2-(3-carboxypropyl)-3-amino-6-(4 methoxyphenyl)pyridazinium bromide], 75 1,2,5,6-tetrahydropyridin-4-yl)methyl-phosphinic acid (TPMPA), 50 6,7-dinitroquinoxaline-2,3-dione (NBQX), 50 AMPA, and 25 kainic acid.

For puff application, the following concentrations were used (in $\mu \mathrm{M}$ ): 100 or 500 CBX, 20,000 HEPES, 20,000 Tris, 500 GABA, 50 AMPA, and 25 kainic acid.

All drugs were purchased from Tocris Bioscience except for CBX, $\mathrm{CoCl}_{2}$, MFA, probenecid, HEPES, and Tris (Sigma-Aldrich). All drug solutions were carboxygenated before application. Probenecid (solved in $1 \mathrm{~m} \mathrm{NaOH}$ ) was added to the carboxygenated extracellular solution and 

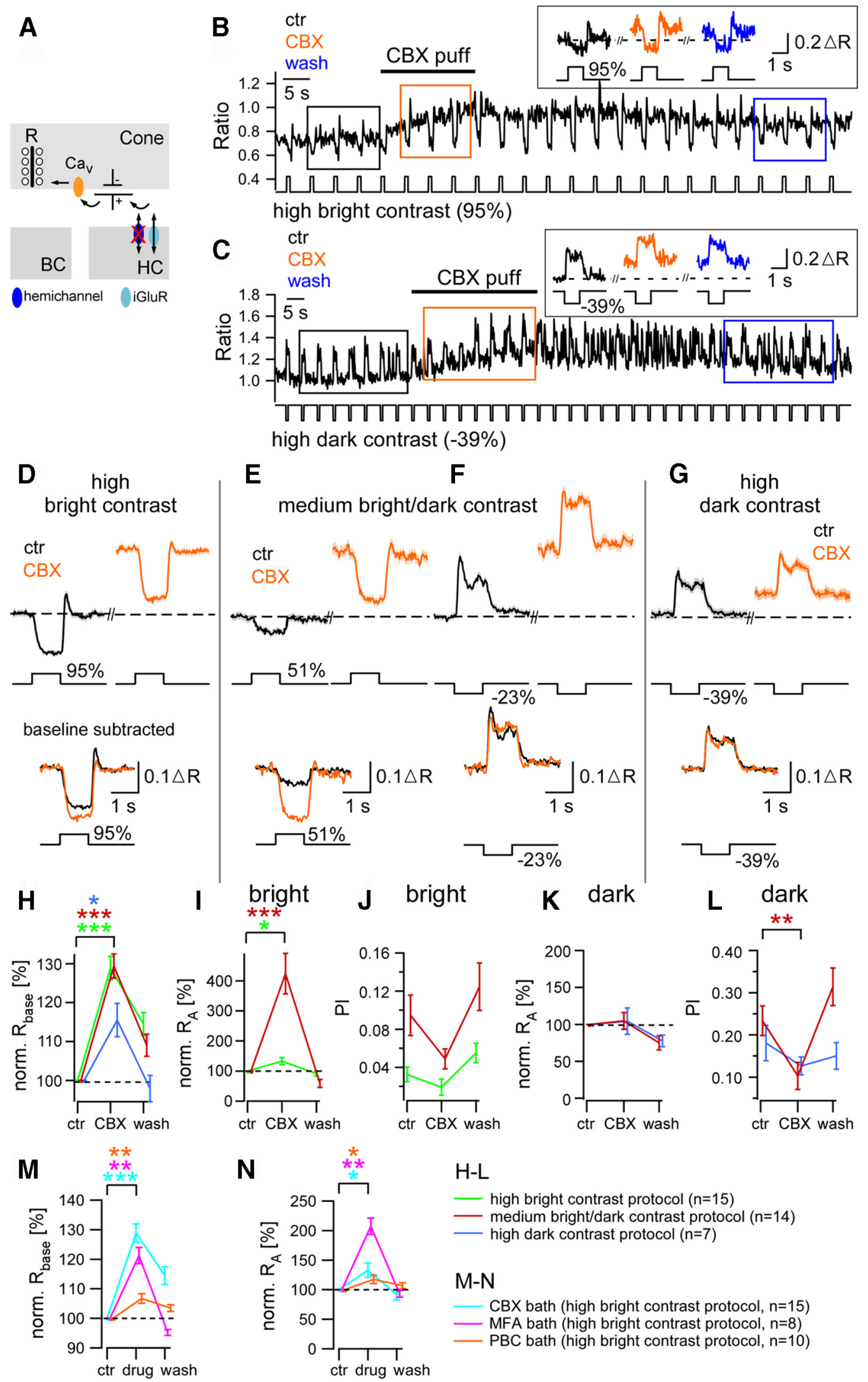

$\mathrm{H}-\mathrm{L}$

- high bright contrast protocol $(n=15)$

medium bright/dark contrast protocol $(n=14)$

high dark contrast protocol $(n=7)$

$\mathrm{M}-\mathrm{N}$

- CBX bath (high bright contrast protocol, $n=15$ )

- MFA bath (high bright contrast protocol, $n=8$ )

- PBC bath (high bright contrast protocol, $n=10$ )

Figure 4. Blocking hemichannels with CBX modulates cone $\mathrm{Ca}^{2+}$ levels and light-evoked $\mathrm{Ca}^{2+}$ responses. $A$, Schematic of the local circuitry between cones and $\mathrm{HCs}$, showing hemichannels (blue) at $\mathrm{HC}$ dendritic tips as proposed key elements in ephaptic feedback. $B$, Exemplary cone $\mathrm{Ca}^{2+}$ responses to bright contrast flashes before (black box), during (orange box), and after (blue box) puff of the hemichannel blocker CBX onto the recorded cone terminals. Inset, $\mathrm{Ca}^{2+}$ signals averaged from the three boxes. $\boldsymbol{C}$, Exemplary cone $\mathrm{Ca}^{2+}$ responses to dark contrast flashes. $\boldsymbol{D}-\mathbf{G}$, Effect of bath-applied $\left(B X\right.$ on the cone $\mathrm{Ca}^{2+}$ signal for the high bright contrast protocol ( $\boldsymbol{D}$; average of $n=15$ cones), the medium bright/dark contrast $(\boldsymbol{E}, \boldsymbol{F}$; average of $n=14$ cones), and the high dark

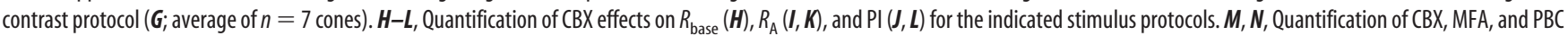
effects on $R_{\text {base }}(\boldsymbol{M})$ and $R_{\mathrm{A}}(\boldsymbol{N})$ for the high bright contrast protocol. Error bars indicate $S E M$. ctr, Control; $R$, ribbon. 


\begin{tabular}{|c|c|c|c|c|}
\hline & Number of mice/slices/cells & Control & Drug & Wash \\
\hline \multicolumn{5}{|l|}{ CBX, bath application } \\
\hline \multicolumn{5}{|c|}{ Bright responses ( $95 \%$ contrast) } \\
\hline Normalized $R_{\text {base }}$ & $2 / 2 / 15$ & 1.0 & $1.289 \pm 0.031^{* * *}$ & $1.145 \pm 0.030^{* * *}$ \\
\hline Normalized $R_{\mathrm{A}}$ & $2 / 2 / 15$ & 1.0 & $1.329 \pm 0.119^{*}$ & $0.913 \pm 0.086$ \\
\hline $\mathrm{Pl}-\mathrm{A}$ & $2 / 2 / 15$ & $0.033 \pm 0.008$ & $0.019 \pm 0.009$ & $0.055 \pm 0.010$ \\
\hline \multicolumn{5}{|c|}{ Bright responses ( $51 \%$ contrast) } \\
\hline Normalized $R_{\text {base }}$ & $2 / 3 / 14$ & 1.0 & $1.293 \pm 0.031^{* * *}$ & $1.090 \pm 0.0284^{*}$ \\
\hline Normalized $R_{\mathrm{A}}$ & $2 / 3 / 14$ & 1.0 & $4.244 \pm 0.669^{* * *}$ & $0.588 \pm 0.129^{* *}$ \\
\hline $\mathrm{PI}-\mathrm{A}^{\mathrm{A}}$ & $2 / 3 / 14$ & $0.094 \pm 0.021$ & $0.048 \pm 0.010$ & $0.124 \pm 0.024$ \\
\hline \multicolumn{5}{|c|}{ Dark responses ( $-23 \%$ contrast) } \\
\hline Normalized $R_{\mathrm{A}}$ & $2 / 3 / 14$ & 1.0 & $1.04 \pm 0.11$ & $0.75 \pm 0.09^{*}$ \\
\hline $\mathrm{Pl}$ & $2 / 3 / 14$ & $0.234 \pm 0.035$ & $0.103 \pm 0.032^{* *}$ & $0.314 \pm 0.044$ \\
\hline \multicolumn{5}{|c|}{ Dark responses ( $-39 \%$ contrast) } \\
\hline Normalized $R_{\text {base }}$ & $1 / 2 / 7$ & 1.0 & $1.155 \pm 0.042^{*}$ & $0.979 \pm 0.033$ \\
\hline Normalized $R_{\mathrm{A}}$ & $1 / 2 / 7$ & 1.0 & $1.044 \pm 0.176$ & $0.775 \pm 0.079$ \\
\hline $\mathrm{PI} \quad \stackrel{n}{n}$ & $1 / 2 / 7$ & $0.180 \pm 0.041$ & $0.126 \pm 0.021$ & $0.150 \pm 0.031$ \\
\hline \multicolumn{5}{|l|}{ CBX, puff application } \\
\hline \multicolumn{5}{|c|}{ Bright responses ( $95 \%$ contrast) } \\
\hline Normalized $R_{\text {base }}$ & $3 / 3 / 32$ & 1.0 & $1.154 \pm 0.013^{* * *}$ & $1.071 \pm 0.013^{* * *}$ \\
\hline Normalized $R_{\mathrm{A}}$ & $3 / 3 / 32$ & 1.0 & $1.395 \pm 0.122^{*}$ & $1.287 \pm 0.090^{* *}$ \\
\hline $\mathrm{Pl}$ & $3 / 3 / 32$ & $0.074 \pm 0.010$ & $0.067 \pm 0.011$ & $0.043 \pm 0.006^{*}$ \\
\hline \multicolumn{5}{|c|}{ Dark responses ( $-39 \%$ contrast) } \\
\hline Normalized $R_{\text {base }}$ & $1 / 1 / 5$ & 1.0 & $1.090 \pm 0.023$ & $1.030 \pm 0.039$ \\
\hline Normalized $R_{\mathrm{A}}$ & $1 / 1 / 5$ & 1.0 & $0.952 \pm 0.037$ & $0.956 \pm 0.049$ \\
\hline 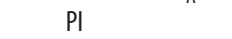 & $1 / 1 / 5$ & $0.167 \pm 0.042$ & $0.090 \pm 0.040$ & $0.154 \pm 0.033$ \\
\hline \multicolumn{5}{|l|}{ MFA, bath application } \\
\hline \multicolumn{5}{|c|}{ Bright responses ( $95 \%$ contrast) } \\
\hline Normalized $R_{\text {base }}$ & $1 / 1 / 8$ & 1.0 & $1.213 \pm 0.028^{* *}$ & $0.952 \pm 0.010^{* *}$ \\
\hline Normalized $R_{\mathrm{A}}$ & $1 / 1 / 8$ & 1.0 & $2.074 \pm 0.139^{* *}$ & $0.933 \pm 0.055$ \\
\hline $\mathrm{Pl}-\mathrm{A}$ & $1 / 1 / 8$ & $0.058 \pm 0.017$ & $0.042 \pm 0.008$ & $0.082 \pm 0.010$ \\
\hline \multicolumn{5}{|c|}{ PBC, bath application } \\
\hline \multicolumn{5}{|c|}{ Bright responses (95\% contrast) } \\
\hline Normalized $R_{\text {base }}$ & $2 / 5 / 10$ & 1.0 & $1.067 \pm 0.016^{* *}$ & $1.035 \pm 0.011^{* *}$ \\
\hline Normalized $R_{\mathrm{A}}$ & $2 / 5 / 10$ & 1.0 & $1.176 \pm 0.071^{*}$ & $1.067 \pm 0.051$ \\
\hline $\mathrm{PI} \quad \stackrel{\mathrm{A}}{-}$ & $2 / 5 / 10$ & $0.015 \pm 0.007$ & $0.022 \pm 0.003$ & $0.022 \pm 0.004$ \\
\hline \multicolumn{5}{|l|}{ Cobalt, bath application } \\
\hline \multicolumn{5}{|c|}{ Bright responses ( $51 \%$ contrast) } \\
\hline Normalized $R_{\text {base }}$ & $1 / 4 / 12$ & 1.0 & $0.872 \pm 0.018^{* * *}$ & $1.114 \pm 0.023^{* *}$ \\
\hline Normalized $R_{\mathrm{A}}$ & $1 / 4 / 12$ & 1.0 & $0.168 \pm 0.043^{* * *}$ & $1.487 \pm 0.231^{*}$ \\
\hline $\mathrm{PI}$ & $1 / 4 / 12$ & $0.082 \pm 0.030$ & $0.258 \pm 0.074$ & $0.066 \pm 0.016$ \\
\hline \multicolumn{5}{|c|}{ Dark responses $(-23 \%$ contrast) } \\
\hline Normalized $R_{\mathrm{A}}$ & $1 / 4 / 12$ & 1.0 & $0.783 \pm 0.104^{*}$ & $0.761 \pm 0.066^{* *}$ \\
\hline $\mathrm{PI}-\mathrm{A}$ & $1 / 4 / 12$ & $0.046 \pm 0.018$ & $0.127 \pm 0.033$ & $0.141 \pm 0.053$ \\
\hline \multicolumn{5}{|c|}{ CBX + NBQX, bath application } \\
\hline \multicolumn{5}{|c|}{ Bright responses ( $51 \%$ contrast) } \\
\hline Normalized $R_{\text {base }}$ & $2 / 3 / 9$ & 1.0 & $1.427 \pm 0.053^{* *}$ & $1.096 \pm 0.022^{* *}$ \\
\hline Normalized $R_{\mathrm{A}}$ & $2 / 3 / 9$ & 1.0 & $5.561 \pm 1.399^{* *}$ & $1.226 \pm 0.267$ \\
\hline $\mathrm{PI} \quad A$ & $2 / 3 / 9$ & $0.063 \pm 0.037$ & $0.028 \pm 0.011$ & $0.136 \pm 0.032$ \\
\hline \multicolumn{5}{|c|}{ Dark responses ( $-23 \%$ contrast) } \\
\hline Normalized $R_{\mathrm{A}}$ & $2 / 3 / 9$ & 1.0 & $0.813 \pm 0.102$ & $0.763 \pm 0.073^{* *}$ \\
\hline $\mathrm{PI} \quad \mathrm{A}$ & $2 / 3 / 9$ & $0.185 \pm 0.036$ & $0.157 \pm 0.038$ & $0.227 \pm 0.032$ \\
\hline \multicolumn{5}{|c|}{ CBX, bath application, with PD168077 } \\
\hline Pooled data from two & & & & \\
\hline Normalized $R_{\text {base }}$ & $1 / 4 / 6$ & 1.0 & $1.295 \pm 0.090^{*}$ & $1.142 \pm 0.034^{*}$ \\
\hline
\end{tabular}

adjusted to $\mathrm{pH} 7.4$ using $1 \mathrm{M} \mathrm{HCl}$. For the $\mathrm{pH}$ buffer solutions, HEPES or Tris was added to the carboxygenated extracellular solution, which was then again carboxygenated for $15 \mathrm{~min}$, and finally adjusted to $\mathrm{pH} 7.4$ using $1 \mathrm{M}$ $\mathrm{NaOH}$ or $1 \mathrm{M} \mathrm{HCl}$, respectively. To exclude osmotic effects in the case of the HEPES application, we used an osmolarity-corrected extracellular solution for some of the HEPES experiments. However, we did not see any differences compared with the recordings with HEPES in the standard solution.

Data analysis. For analyzing light-evoked $\mathrm{Ca}^{2+}$ signals, customwritten scripts for IgorPro (Wavemetrics) were used. Regions of interest were positioned on the cone axon terminals, and the (background- subtracted) ratio acceptor/donor between the fluorescence signal of the FRET donor/acceptor pair eCFP and citrine, respectively, was calculated. A ratio increase represents an elevation in intracellular $\mathrm{Ca}^{2+}$ concentration. Because we focused on relative changes in $\mathrm{Ca}^{2+}$ levels, we refrained from calibrating the setup and give the fluorescence ratio as a proxy of $\mathrm{Ca}^{2+}$ level. Only cells that showed reliable light responses during the control condition, i.e., individual response trials behave similar to the average response, were selected for further analysis (for response quality criterion, see Baden et al., 2013a; for consistency of responses, compare Fig. 4C in Wei et al., 2012). Several response parameters were determined 

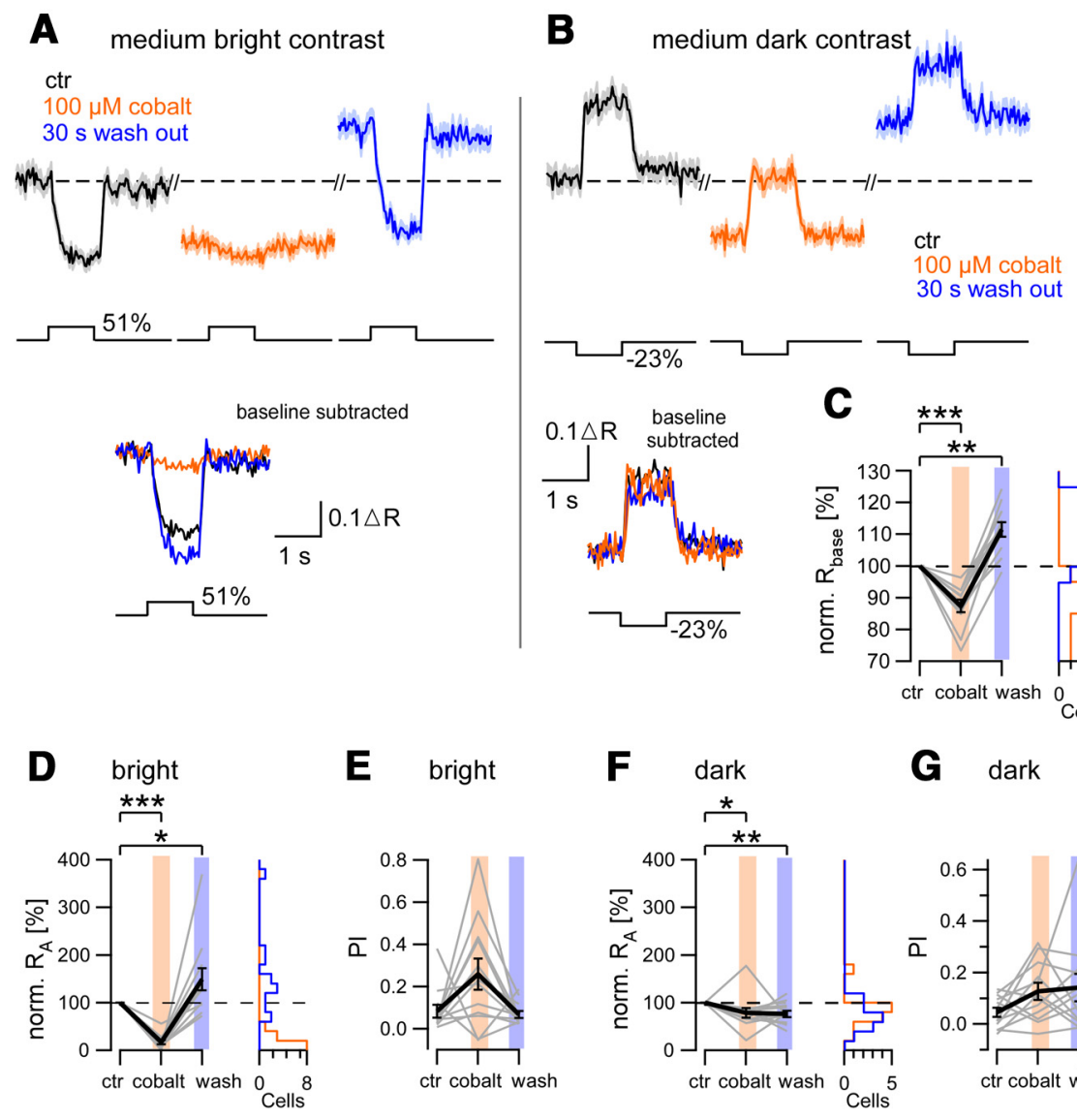

Figure 5. Blocking hemichannels with cobalt at concentrations lower than $100 \mu \mathrm{m}$ recapitulates most of the effects observed for $\mathrm{CBX}$. $\boldsymbol{A}$, Cone $\mathrm{Ca}^{2+}$ responses ( $n=12$ cones averaged) to the medium bright contrast protocol before (ctr, black), during application of cobalt (orange), and during washout (blue). $\boldsymbol{B}$, Cone $\mathrm{Ca}^{2+}$ responses $(n=12$ cones averaged) to the medium dark contrast protocol before (ctr, black), during application of cobalt (orange), and during washout (blue). C-G, Quantification of cobalt effects on $R_{\text {base }}(\boldsymbol{C}), R_{\mathrm{A}}(\boldsymbol{D}, \boldsymbol{F})$, and PI $(\boldsymbol{E}, \boldsymbol{G})$ for the indicated stimulus protocols. Error bars indicate SEM.

using box car-filtered average traces (typically the average of 10 but minimally 3 stimulus trials; box width, $160 \mathrm{~ms}$ ).

For the surround stimulation experiments, we used an approach [see protocols (b) and (c) above] that activated cones in a recording field at different time points within a trial. To determine the time point of the response onset for each cone, its response to the small bar (i.e., the receptive field "center" response) was fitted with a sigmoid. As response onset, we defined the time point when the $\mathrm{Ca}^{2+}$ signal level exceeded a threshold of $1 \mathrm{SD}$ below or above the baseline for bright and dark stimuli, respectively. This response onset was used as a "reference" to determine the following parameters. First, we analyzed how surround stimulation modulated the cone's $\mathrm{Ca}^{2+}$ baseline $\left(R_{\text {base }}\right)$ during a time period of $0.5 \mathrm{~s}$ before response onset (Figs. $1 E_{1}, 2 B_{1}$ ). At this time point, the bar stimulus was still in the cone's surround ( $10 \mu \mathrm{m}$ away from the cone's position) and evoked a maximal effect on the cone resting $\mathrm{Ca}^{2+}$ level (Fig. $1 H$ ). Second, we analyzed how surround stimulation modulated the response amplitude $\left(R_{\text {amp }}\right)$ with the bar stimulus inside the cone's receptive field center relative to $R_{\text {base }}$ (for details, see Figs. $1 E_{2}, 2 B_{2}$ ).

For the receptive field measurement experiments [see protocol (d) above], we pseudo-randomly presented a stimulus bar at several different positions relative to the recorded cones (Fig. 2D). For each stimulus position, the cone $\mathrm{Ca}^{2+}$ level was extracted (mean of 20 trials), plotted against stimulus position (Fig. 2E), and fitted with a Gaussian. After baseline subtraction, normalization, and adjustment for position of the cone (estimated by the position of the Gaussian peak), the data were analyzed at the population level (Fig. 2F).

For the full-field flash stimulation experiments, we also determined $R_{\text {base }}$ (Fig. 3C), but instead of $R_{\text {amp }}$, we used the response area under the trace $\left(R_{\mathrm{A}}\right)$ as a measure of response size. Finally, we determined the
G dark

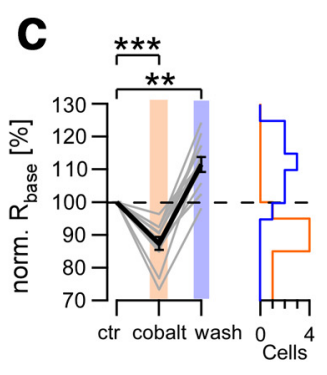

"peakedness index" (PI), which was defined as $\left(A_{\text {peak }}-A_{\text {plateau }}\right) /\left(A_{\text {peak }}+A_{\text {plateau }}\right)$, with $A_{\text {peak }}$ being the amplitude of the response peak and $A_{\text {plateau }}$ being the amplitude of the response plateau (Fig. 3D).

The drug effects on the different response parameters were statistically evaluated using the Wilcoxon rank-sum test and the Wilcoxon signed-rank test. Alpha was 0.05 , and $p$ values $<0.05$ were considered as significant $\left.{ }^{*}\right)$, $<0.01\left(^{* *}\right)$, and $<0.001\left(^{* * *}\right)$. Using the stimulation protocols described above, we did not find any significant differences of drug effects between functional $\mathrm{S}$ and $\mathrm{M}$ cones (Baden et al., 2013b) and, therefore, decided to pool data from both cone types for analysis. If not indicated otherwise, errors are given as SEM.

\section{Results}

Imaging $\mathrm{Ca}^{2+}$ levels in cone axon terminals as a proxy for cone output

Recent studies measured HC feedback at the level of cones using electrical recordings from the cone soma (for review, see Thoreson and Mangel, 2012). Whole-cell patch-clamp recordings strongly suggest that HCs provide feedback to cones by changing the activation level of voltagegated $\mathrm{Ca}^{2+}$ channels (VGCCs) in the cone terminal (Verweij et al., 1996; Kraaij et al., 2000; Hirasawa and Kaneko, 2003; Fahrenfort et al., 2009). With all three proposed feedback mechanisms eventually acting through modulation of VGCC activation (for review, see Kamermans and Fahrenfort, 2004), in the present study, we monitored HC feedback by optically recording light-evoked $\mathrm{Ca}^{2+}$ signals in cone axon terminals in retinal slices using $2 \mathrm{P}$ microscopy. To this end, we used the transgenic HR2.1:TN-XL mouse line (Wei et al., 2012), in which cones selectively express the $\mathrm{Ca}^{2+}$ indicator TN-XL (Mank et al., 2006; Fig. $1 A$ ). Because transmitter release from cones was shown to directly depend on presynaptic $\mathrm{Ca}^{2+}$ (Thoreson, 2007; Jackman et al., 2009), this approach allows for a direct measurement of the consequences that $\mathrm{HC}$ feedback has on cone output with the cone terminal $\mathrm{Ca}^{2+}$ as proxy for cone synaptic output (Thoreson, 2007; Jackman et al., 2009).

\section{Surround stimulation modulates light-evoked $\mathrm{Ca}^{2+}$ responses in individual cone axon terminals}

Before pharmacologically dissecting the different hypothesized $\mathrm{HC}$ feedback mechanisms, we investigated how light stimulation in a cone's surround affects its $\mathrm{Ca}^{2+}$ response. A classical experiment to study $\mathrm{HC}$ feedback is to stimulate a cone with light spots of different diameters, i.e., a small spot to evoke mainly the receptive field (RF) center response and a large spot to evoke the RF's combined center/surround response. The effect of $\mathrm{HC}$ feedback on the cone can then be isolated by subtracting the responses to large and small spots (Baylor et al., 1971). Here, we modified this stimulus paradigm to allow for recording from many cones in a slice simultaneously: We first presented a small bright bar (40 $\mu \mathrm{m}$ wide) at different consecutive positions (10 $\mu \mathrm{m}$ step width) along the slice while recording the $\mathrm{Ca}^{2+}$ signals in 5-10 cone terminals simultaneously (Fig. $1 B, C$ ). Then this sequence was 
repeated, but using a large bright bar (500 $\mu \mathrm{m}$ wide). Our sequential approach eliminated the need for recording timeconsuming precise alignment of the small spot with a cone. The responses to the two bars can then be extracted for each cone (Fig. 1D) and, after appropriate alignment of the $\mathrm{Ca}^{2+}$ traces for cone position, compared between the recorded cones.

We analyzed how large, bright stimuli in the surround modulate the resting $\mathrm{Ca}^{2+}$ level $\left(R_{\text {base }}\right.$; Fig. $\left.1 E_{1}\right)$ and the relative amplitude of the cone response $\left(R_{\mathrm{amp}}\right.$; Fig. $\left.1 E_{2}\right)$. We found that large, bright stimuli in the surround reduced $R_{\text {base }}$ (by $3.4 \pm$ $0.8 \%, n=24, p<0.001$ ) and $R_{\mathrm{amp}}$ (by $6.2 \pm 3.3 \%, p=0.03$; Fig. $1 F$ ), suggesting that cones in our slice preparation are modulated by lateral interactions that are consistent with HC feedback. Note that because of our stimulus design, the large bar covered only approximately half of the cone's surround when $R_{\text {base }}$ and $R_{\mathrm{amp}}$ were determined. Therefore, our measurements likely represent an underestimate of the surround effect. To exclude the possibility of "flooring" the cone $\mathrm{Ca}^{2+}$ levels (or the leaving the sensitivity range of the biosensor), both of which would appear like a reduction in $R_{\mathrm{amp}}$, we only pooled data of responses to low-contrast stimuli (16 and 26\% Weber contrast) and used a brighter test stimulus (either a contrast-increasing step, as in Fig. $1 D$, or separate trials with a higher-contrast stimulus) to verify that $\mathrm{Ca}^{2+}$ levels can be further decreased (for details, see Fig. $1 D$ legend). Next, we analyzed how increasing the contrast alters the surround effect on $R_{\text {base }}$. Already at $16 \%$ Weber contrast, $R_{\text {base }}$ was significantly reduced by $1.8 \pm 0.7 \%(n=14, p=0.02)$; at $72 \%$ contrast, the highest contrast tested, $R_{\text {base }}$ was reduced by $8.1 \pm 1.1 \%(n=23$, $p<0.001$ ), suggesting that stimulating the HC network with higher contrasts leads to larger feedback effects on cone $\mathrm{Ca}^{2+}$ signals (Fig. $1 G$ ). The surround stimulation-induced effects on cone resting $\mathrm{Ca}^{2+}$ level were already observed when the bar stimulus was $>200 \mu \mathrm{m}$ distant from the measured cones and increased further when the bar approached the cones (Fig. $1 H$ ), suggesting that HCs with their large receptive fields are involved in the observed effects. These data are in agreement with the published length constant of mouse HCs $(\sim 115 \mu \mathrm{m}$; Shelley et al., 2006). We confirmed that HC feedback was involved by applying CBX, a commonly used blocker for hemichannelmediated HC feedback (Kamermans et al., 2001). CBX significantly reduced the surround effects on $R_{\text {base }}$ by $45 \%$ (control, $-0.073 \pm 0.008$; CBX, $-0.04 \pm 0.012$; absolute ratio values; $n=10 ; p=0.004$; Fig. $1 I$ ), supporting that lateral $\mathrm{HC}$ feedback is responsible for the observed surround effect.

We also asked how darker-than-background bar stimuli affect cone $\mathrm{Ca}^{2+}$ signals (Fig. 2). Small and large dark bars elicited responses of opposite polarity compared with those during stimulation with bright bars (compare Figs. 1D, 2A). In contrast to bright bars, dark stimuli presented to the surround led to an increase in $R_{\text {base }}$ (by $5.3 \pm 0.8 \%, n=15, p<0.001$ ) and in $R_{\mathrm{amp}}$
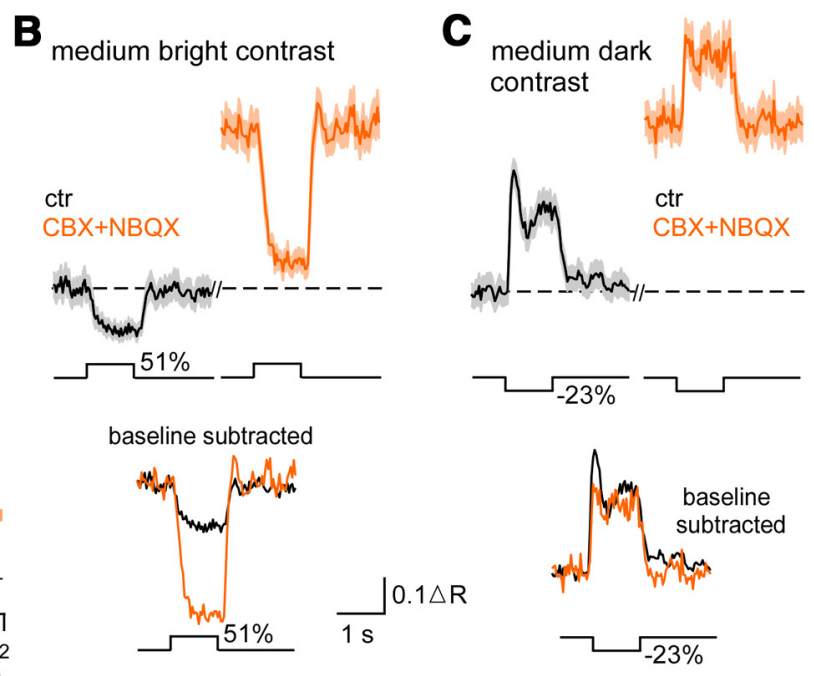

F bright

G dark

H dark
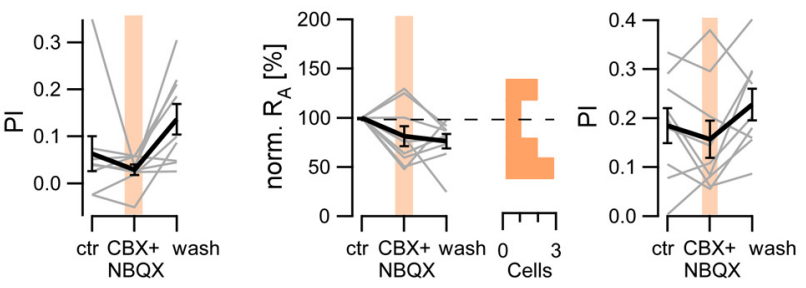

Figure 6. Blocking both hemichannels and ionotropic glutamate receptors on horizontal cells modulates cone $\mathrm{Ca}^{2+}$ levels and light-evoked $\mathrm{Ca}^{2+}$ responses. $A$, Schematic of the local circuitry between cones and HCs showing both hemichannels (blue) and ionotropic glutamate receptors (iGluRs, light blue) at HC dendritic tips mediating ephaptic feedback. $B, C$, Coapplication of CBX and CBX (compare Fig. 4). $\boldsymbol{D}-\boldsymbol{H}$, Quantification of $\mathrm{CBX}+\mathrm{NBQX}$ effects on $R_{\text {base }}(\boldsymbol{D}), \mathrm{R}_{\mathrm{A}}(\boldsymbol{E}, \boldsymbol{G})$, and PI $(\boldsymbol{F}, \boldsymbol{H})$ for the indicated stimulus protocols. Error bars indicate SEM. ctr, Control; R, ribbon.

(by $23.0 \pm 7.3 \%, p=0.003$; Fig. $2 C$ ). To test whether this excitatory surround effect resulted from summation of responses from neighboring, gap-junctionally coupled cones rather than from $\mathrm{HC}$ feedback, we measured the receptive field size of cones. To this end, we presented a small dark bar stimulus ( $40 \mu \mathrm{m}$ wide) pseudo-randomly at different positions (offset between neighboring positions, $10 \mu \mathrm{m}$ ) relative to a set of cones (Fig. $2 D$ ). The average cone $\mathrm{Ca}^{2+}$ level was then plotted as a function of stimulus position (Fig. $2 E, F$ ), from which we estimated an upper limit of $20 \mu \mathrm{m}$ for the cone receptive field size (Fig. $2 G$; for details, see Fig. 2 legend). With an average distance of $\sim 10 \mu \mathrm{m}$ between two mouse cones (estimated from the cone density of $12,400 \mathrm{~mm}^{-2}$; Jeon et al., 1998), this suggests that photoreceptor coupling is weak under our experimental conditions. Thus, the observed long-ranging excitatory effects of the dark surround stimulation experiments on cone $\mathrm{Ca}^{2+}$ levels cannot be explained by direct photoreceptor interactions and are likely mediated by HCs.

In summary, presenting bright and dark stimuli in the surround of a cone modulated both its baseline $\mathrm{Ca}^{2+}$ level and relative response amplitude. Cone $\mathrm{Ca}^{2+}$ responses were smaller when a bright stimulus was presented to the surround, as expected for "classical" lateral inhibition and contrast enhancement (for review, see Thoreson and Mangel, 2012). However, when a dark stimulus was present in the surround, cone $\mathrm{Ca}^{2+}$ responses became larger, a finding that is consistent with the positive $\mathrm{HC}$ feedback recently described in different species (mouse not tested; Jackman et al., 2011). 
A

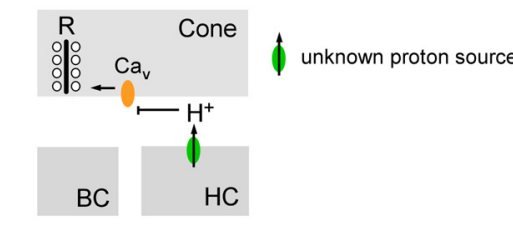

B

C

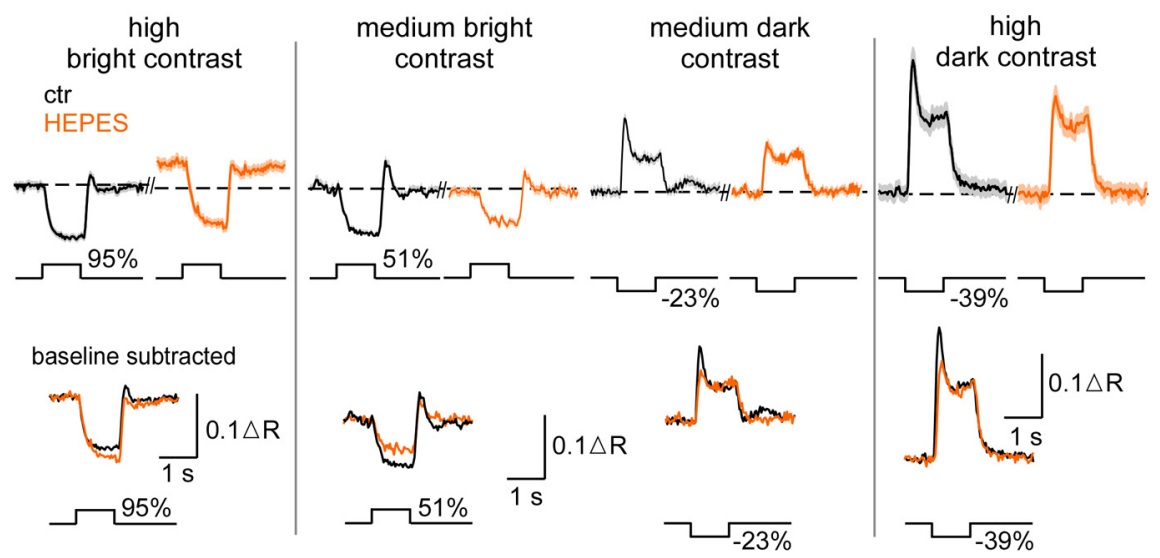

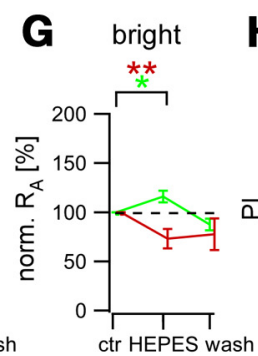

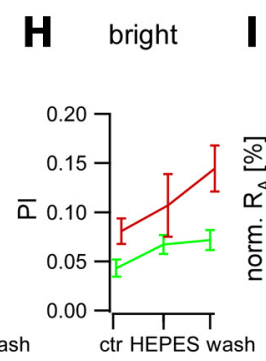

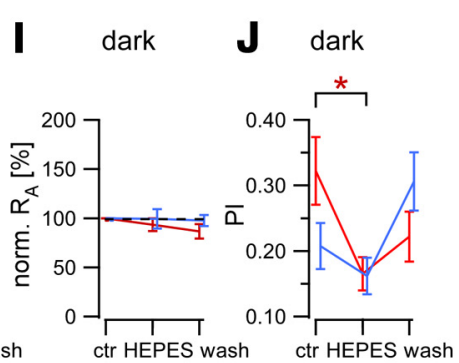

- high bright contrast protocol $(n=28)$ - medium bright/dark contrast protocol $(n=16)$ - high dark contrast protocol $(n=17)$

Figure 7. Clamping pH in the synaptic cleft has contrast-dependent effects on cone $\mathrm{Ca}^{2+}$ signals. $\boldsymbol{A}$, Schematic of the local circuitry between cones and $\mathrm{HCS}$ illustrating that the activity of voltage-gated calcium channels (orange) in the cone terminal depends on the $\mathrm{pH}$ in the synaptic cleft. $\boldsymbol{B}-\boldsymbol{E}$, Effect of the $\mathrm{pH}$ buffer HEPES on the cone $\mathrm{Ca}^{2+}$ signal for the high bright contrast ( $\boldsymbol{B}$; average of $n=28$ cones), the medium bright/dark contrast ( $C, D$; average of $n=16$ cones), and the high dark contrast protocol $\left(\boldsymbol{E}\right.$; average of $n=17$ cones). $\boldsymbol{F}-\boldsymbol{J}$, Quantification of HEPES effects on $R_{\text {base }}(\boldsymbol{F}), R_{\mathrm{A}}(\boldsymbol{G}, \boldsymbol{I})$, and $\mathrm{PI}(\boldsymbol{H}, \boldsymbol{J})$ for the indicated stimulus protocols. Error bars indicate SEM. ctr, Control; R, ribbon.

\section{Pharmacological dissection of hypothesized feedback mechanisms}

For pharmacological dissection of the different hypothesized feedback mechanisms from HCs to cones (Fig. 3A), we used fullfield flash protocols. Whereas the three stimulation protocols (Fig. 3B) had slightly different background levels, the differences were within a single log unit, and thus we assumed similar retinal adaptation states (for details, see Materials and Methods and Table 1). The responses to the full-field flashes $(\sim 2 \mathrm{~mm}$ in diameter) are expected to contain a combination of the cone RF center and surround component, the latter mediated by HC feedback. To dissect the feedback that modulates cone $\mathrm{Ca}^{2+}$, we blocked, selectively or in combination, the three proposed feedback mechanisms (hemichannel mediated, $\mathrm{pH}$ mediated, and GABAergic), or modulated HC activity in general. We analyzed the pharmacological effects on $R_{\text {base }}$ on the response area under the trace $R_{\mathrm{A}}$ (Fig. 3 C) and, in addition, on the PI (see Materials and Methods) to capture the ratio between transient and sustained response components (Fig. 3D).

Based on our bar stimulus experiments, we expected that pharmacologically blocking feedback should (1) increase $R_{\text {base }}$, because eliciting feedback by bright stimuli (= hyperpolarizing $\mathrm{HCs}$ ) in the cone's surround resulted in a decrease of the $\mathrm{Ca}^{2+}$ level (Fig. 1); (2) increase $R_{\mathrm{A}}$ to bright flashes, as we observed "lateral inhibition" for bright stimuli (Fig. 1 ); and (3) reduce $R_{\mathrm{A}}$ to dark flashes, as we observed "lateral excitation" for dark stimuli (Fig. 2).

Hemichannel-mediated (ephaptic) feedback modulates $\mathrm{Ca}^{2+}$ levels and light-evoked $\mathrm{Ca}^{2+}$ signals in cone axon terminals

Ephaptic feedback modulating the VGCC activity in cones requires conductances at HC dendrites to effectively change the local cone membrane potential (for review, see Kamermans and Fahrenfort, 2004). In fish retina, both hemichannels $(\sim 60 \%)$ and ionotropic glutamate receptors (iGluRs; $\sim 40 \%$ ) were proposed to contribute to ephaptic feedback (Fahrenfort et al., 2009). Fish retinal hemichannels are formed by connexin 55.5 (Shields et al., 2007; Klaassen et al., 2011) and Pannexin1 (Prochnow et al., 2009). In the mouse retina, the connexins that form functional hemichannels in HC dendrites have not yet been identified (Deans and Paul, 2001; Janssen-Bienhold et al., 2009). Recently, it was reported that Pannexin1 is also present at mouse $\mathrm{HC}$ dendritic tips and thus represents a promising hemichannel candidate (Kranz et al., 2013). Like fish HCs, mouse HCs express iGluRs (Schubert et al., 2006; Ströh et al., 2013) that could contribute to ephaptic feedback.

To investigate whether hemichannelmediated (ephaptic) feedback (Fig. 4A) plays a role in the mouse retina, we used CBX (Kamermans et al., 2001), which blocks both connexin- and pannexin-formed hemichannels (Bruzzone et al., 2005). Application of CBX affected the light-evoked cone $\mathrm{Ca}^{2+}$ signals in several ways: (1) $R_{\text {base }}$ increased significantly (Fig. $4 B-H$; for statistics, see Table 2); (2) $R_{\mathrm{A}}$ increased for bright flashes (Fig. $4 D, I$ ) but remained unchanged for dark flashes (Fig. $4 G, K$ ); and (3) the PI for dark flash-evoked responses decreased (Fig. $4 F, L$ ) but remained unchanged for bright flashes (Fig. $4 J$ ). Because CBX (a glycyrrhetinic acid derivative) does not only block hemichannels but may have unspecific side effects, we also tested two additional, structurally different blockers: MFA (a flufenamic acid derivative) to block connexin-formed hemichannels (Pan et al., 2007) and PBC to selectively block Pannexin1-formed hemichannels (Silverman et al., 2008; Vroman et al., 2014). The reasoning was that if the observed CBX effect was dominated by unspecific action not related to blocking hemichannels, then the other two drugs, MFA and PBC, which have different side effects [i.e., on $\mathrm{GABA}_{\mathrm{A}}$ receptors (Smith et al., 2004) and TRPV channels (Bang et al., 2007), respectively], should affect the $\mathrm{Ca}^{2+}$ signals 


\begin{tabular}{|c|c|c|c|c|}
\hline & Number of mice/slices/cells & Control & Drug & Wash \\
\hline \multicolumn{5}{|l|}{ HEPES, bath application } \\
\hline \multicolumn{5}{|c|}{ Bright responses (95\% contrast) } \\
\hline Normalized $R_{\text {base }}$ & $4 / 9 / 28$ & 1.0 & $1.076 \pm 0.020^{* *}$ & $1.035 \pm 0.023$ \\
\hline Normalized $R_{\mathrm{A}}$ & $4 / 9 / 28$ & 1.0 & $1.158 \pm 0.059^{*}$ & $0.875 \pm 0.058^{* *}$ \\
\hline $\mathrm{Pl}$ & $4 / 9 / 28$ & $0.043 \pm 0.008$ & $0.067 \pm 0.009$ & $0.071 \pm 0.010^{*}$ \\
\hline \multicolumn{5}{|c|}{ Bright responses ( $51 \%$ contrast) } \\
\hline Normalized $R_{\text {base }}$ & $2 / 8 / 16$ & 1.0 & $0.992 \pm 0.018$ & $1.007 \pm 0.030$ \\
\hline Normalized $R_{\mathrm{A}}$ & $2 / 8 / 16$ & 1.0 & $0.729 \pm 0.097^{* *}$ & $0.774 \pm 0.159^{* *}$ \\
\hline $\mathrm{PI} \quad n$ & 2/8/16 & $0.080 \pm 0.013$ & $0.107 \pm 0.031$ & $0.144 \pm 0.023^{*}$ \\
\hline \multicolumn{5}{|c|}{ Dark responses ( $-23 \%$ contrast) } \\
\hline Normalized $R_{\mathrm{A}}$ & $2 / 8 / 16$ & 1.0 & $0.935 \pm 0.064$ & $0.865 \pm 0.075$ \\
\hline $\mathrm{PI}$ & $2 / 8 / 16$ & $0.322 \pm 0.051$ & $0.165 \pm 0.026^{*}$ & $0.222 \pm 0.038$ \\
\hline \multicolumn{5}{|c|}{ Dark responses ( $-39 \%$ contrast) } \\
\hline Normalized $R_{\text {base }}$ & $3 / 3 / 17$ & 1.0 & $0.988 \pm 0.007$ & $1.017 \pm 0.014$ \\
\hline Normalized $R_{\mathrm{A}}$ & $3 / 3 / 17$ & 1.0 & $0.991 \pm 0.098$ & $0.974 \pm 0.056$ \\
\hline 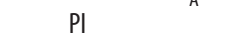 & $3 / 3 / 17$ & $0.207 \pm 0.035$ & $0.161 \pm 0.028$ & $0.305 \pm 0.044^{*}$ \\
\hline \multicolumn{5}{|l|}{ HEPES, puff application } \\
\hline \multicolumn{5}{|c|}{ Dark responses ( $-39 \%$ contrast) } \\
\hline Normalized $R_{\text {base }}$ & $3 / 3 / 24$ & 1.0 & $1.021 \pm 0.011$ & $1.028 \pm 0.015^{*}$ \\
\hline Normalized $R_{\mathrm{A}}$ & $3 / 3 / 24$ & 1.0 & $0.996 \pm 0.047$ & $0.977 \pm 0.047$ \\
\hline $\mathrm{PI}$ & $3 / 3 / 24$ & $0.241 \pm 0.027$ & $0.182 \pm 0.024^{* *}$ & $0.169 \pm 0.020^{* *}$ \\
\hline \multicolumn{5}{|l|}{ Tris, puff application } \\
\hline \multicolumn{5}{|c|}{ Dark responses ( $-39 \%$ contrast) } \\
\hline Normalized $R_{\text {base }}$ & $1 / 2 / 13$ & 1.0 & $1.008 \pm 0.008$ & $1.008 \pm 0.010$ \\
\hline Normalized $R_{\mathrm{A}}$ & $1 / 2 / 13$ & 1.0 & $1.037 \pm 0.070$ & $1.060 \pm 0.048$ \\
\hline $\mathrm{PI}$ & $1 / 2 / 13$ & $0.196 \pm 0.054$ & $0.158 \pm 0.054(p=0.08)$ & $0.202 \pm 0.057$ \\
\hline
\end{tabular}

differently. We found similar results with all three drugs (Fig. $4 M, N$; Table 2), suggesting that the observed effect was indeed very likely caused by blocking hemichannels.

These results suggest that hemichannel-mediated feedback acts on different aspects of cone terminal $\mathrm{Ca}^{2+}$ : it adjusts the basal $\mathrm{Ca}^{2+}$ level and modulates the bright and dark flash-evoked responses differentially. That the response size is only affected for bright flashes suggests that the effect of hemichannel-mediated feedback on the $\mathrm{Ca}^{2+}$ signal strongly depends on contrast polarity. Finally, our results indicate that hemichannel-mediated feedback renders the dark flash-evoked $\mathrm{Ca}^{2+}$ responses more transient.

To further corroborate the presence of hemichannelmediated feedback in the mouse retina, in particular because CBX was reported to have unspecific effects on HC light responses (Vessey et al., 2004), we applied cobalt, which was also shown to block hemichannels (Fahrenfort et al., 2004), but without significantly affecting HC light responses (Thoreson and Burkhardt, 1990; Vigh and Witkovsky, 1999). At a concentration of $100 \mu \mathrm{M}$, cobalt reduced $R_{\text {base }}$ (Fig. $5 A-C$ ) and $R_{\mathrm{A}}$ for both bright and dark flashes (Fig. $5 D, F$ ), which was probably attributable to cobalt directly inhibiting VGCCs (Corey et al., 1984; Liu et al., 2013). When the cobalt concentration decreased during the first $30 \mathrm{~s}$ of washout, both $R_{\text {base }}$ (Fig. $5 C$ ) and $R_{\mathrm{A}}$ increased for bright flashes (Fig. $5 D$ ) compared with the precobalt control, reminiscent of the CBX condition (Fig. 4, compare $H, I$ ). A possible interpretation of these results is that at lower cobalt concentrations, the blocking effect on hemichannels outweighs the direct inhibition of VGCCs, in line with a recent study showing that cobalt concentrations lower than $100 \mu \mathrm{M}$ increase $\mathrm{Ca}^{2+}$ signals in rat photoreceptors (Liu et al., 2013). It is unlikely that the CBX-like effect caused by the low cobalt is caused by inhibition of $\mathrm{GABA}_{\mathrm{A}}$ receptors in the outer retina (Kaneko and Tachibana, 1986), because GABA receptor blockers did not affect cone
$\mathrm{Ca}^{2+}$ responses under our conditions (see below). Why the PI did not change significantly with low cobalt remained unclear (Fig. $5 E, G)$.

Blocking hemichannels increased the basal $\mathrm{Ca}^{2+}$ level in mouse cones, a finding that is in contrast to studies in fish cones. In the fish retina, under resting conditions, the current through hemichannels leads to a voltage drop in the synaptic cleft, thus leading to a local depolarization of the cone axon terminal and an increase in $\mathrm{Ca}^{2+}$ level (Kamermans and Fahrenfort, 2004). Blocking hemichannels should reduce this voltage drop, thereby hyperpolarizing the cone axon terminal. Consequently, the result would be a decrease in basal $\mathrm{Ca}^{2+}$ level and not an increase as observed in our experiments. To test whether a current through iGluRs is related to the unexpected effect of CBX on $R_{\text {base }}$ observed in mouse cones, we blocked iGluRs with NBQX and coapplied CBX (Fig. 6A). However, as for CBX alone, blocking both hemichannels and iGluRs resulted in an increase in $R_{\text {base }}$ (Fig. $6 B-D$ ) and in $R_{\mathrm{A}}$ to bright flashes (Fig. $6 E$ ), whereas $R_{\mathrm{A}}$ to dark flashes did not change (Fig. $6 G$ ); moreover, there was no effect on PI (Fig. 6F,H). The effects of NBQX and CBX on $R_{\text {base }}$ were apparently additive: $R_{\text {base }}$ for CBX alone $(1.29 \pm 0.03, n=14)$ was significantly smaller $(p=0.049)$ than for CBX and NBQX together $(1.43 \pm 0.05, n=9)$, arguing against substantial side effects of CBX on iGluRs in HCs (Tovar et al., 2009). Moreover, the finding that NBQX adds to the CBX effect on $R_{\text {base }}$ argues against the possibility that CBX abolished HC light responses by strongly hyperpolarizing HCs (Kamermans et al., 2001; Vessey et al., 2004) because of the lack of cation influx through hemichannels. Notably, our findings that PBC caused similar effects as CBX (Fig. $4 M, N$ ) supports this conclusion because PBC selectively blocks Pannexin1-formed hemichannels (Silverman et al., 2008) and leaves current flow through connexin-formed hemichannels intact, leading to a weaker HC hyperpolarization. 
A

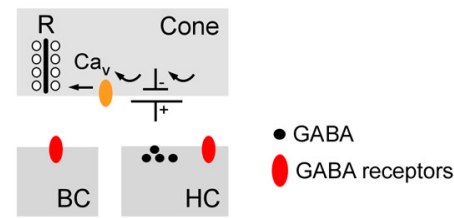

B

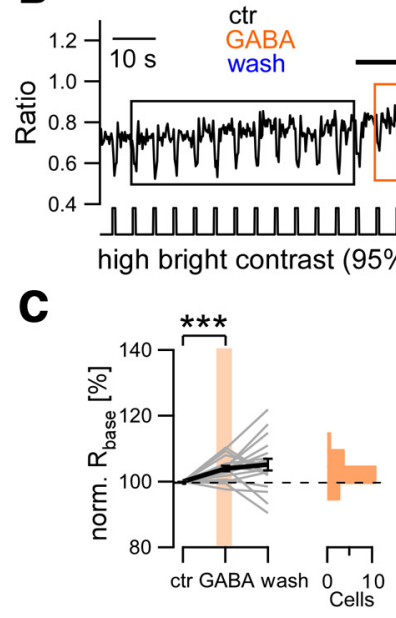

GABA puff
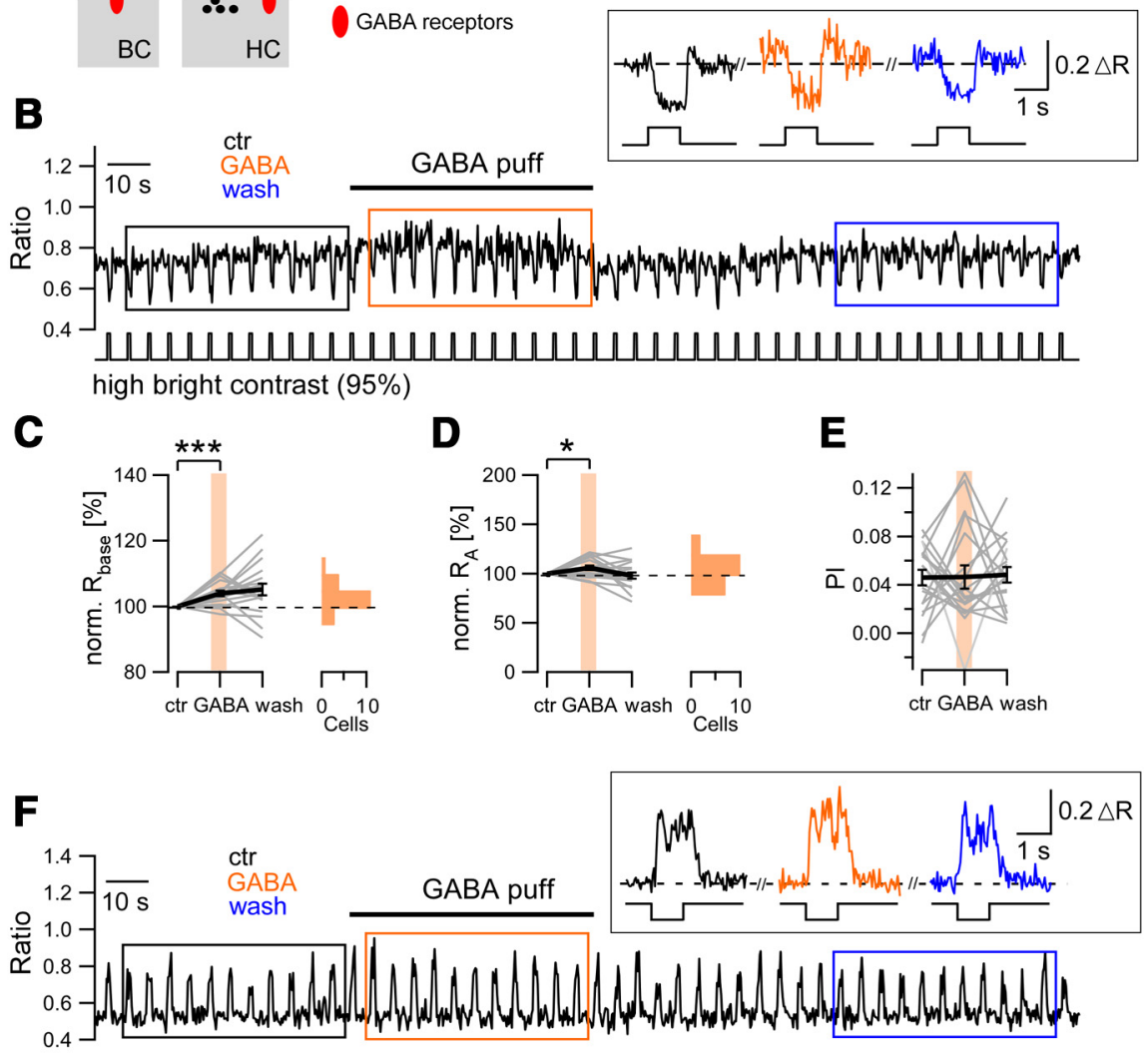

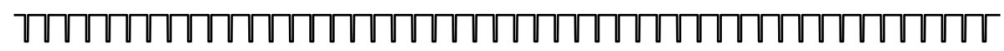
high dark contrast (-39\%)

G

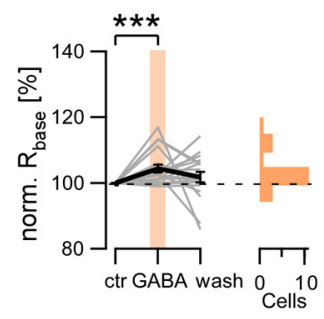

D

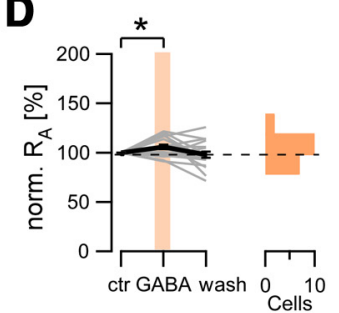

E

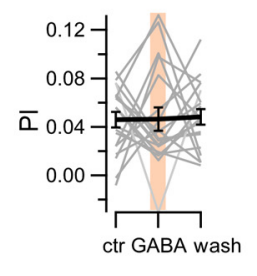

experiments. It is unlikely that uncoupling of the HC network by CBX affects feedback substantially because the pannexin-selective blocker PBC (Silverman et al., 2008), which is expected to leave the connexin-coupled horizontal cell network (Shelley et al., 2006) intact, had similar effects as CBX (Fig. $4 M, N$ ). Thus, the increase in $R_{\text {base }}$ after blocking hemichannels in the mouse retina cannot be explained by uncoupling of the rodcone or HC networks or a change in current through iGluRs. In fact, that CBX increased $R_{\text {base }}$ with full-field flashes is consistent with our surround stimulation experiments (Fig. 1), where the reduction in $R_{\text {base }}$ by light in the surround is counteracted by CBX.

In summary, blocking hemichannels in the mouse retina resulted in an increase in cone $\mathrm{Ca}^{2+}$ level and larger bright flashevoked responses, whereas in the case of dark flash-evoked responses, mainly the kinetics (and less the size) was affected. Note that the demonstration of a hemichannelmediated feedback in mouse is not equivalent to a direct proof of ephaptic feedback, i.e., the electrical signal transfer from membrane to membrane, in particular since hemichannels may also modulate cone voltage via chemical (protonmediated) pathways (Vroman et al., 2014). Nevertheless, an ephaptic feedback mechanism through connexin- and/or pannexin-formed hemichannels may be the most likely explanation for our results.
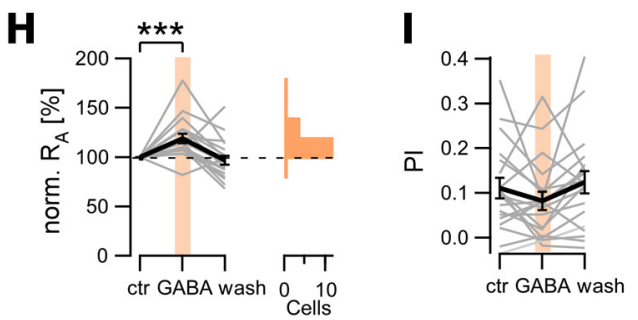

Figure 8. GABA modulates cone $\mathrm{Ca}^{2+}$ signals. $A$, Schematic of the local circuitry between cones and $\mathrm{HC}$ s showing $\mathrm{HCs}$ releasing $G A B A$ into synaptic cleft. $B$, Exemplary cone $\mathrm{Ca}^{2+}$ responses to repetitive high bright contrast stimulation before, during, and after a GABA puff onto the cone terminals. Inset, Averaged $\mathrm{Ca}^{2+}$ signals for different time windows (as indicated by the boxes). $\boldsymbol{C}-\boldsymbol{E}$, Quantification of GABA effects on $R_{\text {base }}\left(\boldsymbol{C}, R_{\mathrm{A}}(\boldsymbol{D})\right.$, and PI $(\boldsymbol{E})$ for bright contrast-evoked responses. $\boldsymbol{F}$-I, Same experiment as in $\boldsymbol{B}-\boldsymbol{E}$ but for the high dark contrast protocol. Error bars indicate SEM. ctr, Control; $R$, ribbon.

The CBX-induced increase in the basal cone $\mathrm{Ca}^{2+}$ level might also be caused by uncoupling of the gap-junctionally coupled photoreceptor and/or horizontal cell network. To test the possibility that the CBX-induced increase in $R_{\text {base }}$ was caused by disrupting the gap-junctionally coupled rod-cone network (Tsukamoto et al., 2001), we reduced photoreceptor coupling by applying the dopamine receptor 4 (DR4) agonist PD168077 for $\geq 1 \mathrm{~h}$ (Li et al., 2013) and then applied CBX. In the presence of the DR4 agonist, the CBX-induced increase in $R_{\text {base }}$ was comparable to the CBX-only condition ( $p=0.89$; control, $n=29$; PD168077, $n=6$; Table 2), suggesting that the coupling state of the rod-cone network has no detectable effect on cone $\mathrm{Ca}^{2+}$ signals in our effects on $R_{\mathrm{A}}$ depending on the stimulus pH-mediated feedback modulates lightevoked $\mathrm{Ca}^{2+}$ signals in cone axon terminals in a contrast-dependent way To test the $\mathrm{pH}$-mediated feedback hypothesis (Fig. 7A), we buffered $\mathrm{pH}$ changes in the synaptic cleft with HEPES (Hirasawa and Kaneko, 2003; Vessey et al., 2005; Fahrenfort et al., 2009). Except for the stimulus protocol with the lowest background intensity (high bright contrast; Fig. $7 B, F)$, HEPES did not affect $R_{\text {base }}$ (Fig. 7C-F; for statistics, see Table 3). For bright flashes, HEPES had differential contrast: responses to high-contrast bright flashes increased (Fig. $7 B, G)$, whereas responses to medium-contrast bright flashes decreased (Fig. 7C,G). HEPES did not affect PI of bright flashevoked responses (Fig. $7 H$ ). These findings point at different roles for $\mathrm{pH}$-mediated feedback in shaping cone responses to bright flashes: attenuation for high-contrast stimuli and amplification for low-contrast stimuli. For dark responses, HEPES did not significantly change $R_{\mathrm{A}}$ (Fig. $7 I$ ) but affected the response kinetics by decreasing the PI (Fig. $7 J$ ). Because HEPES has an aminosulfonate moiety that inhibits hemichannels at high concentrations (Bevans and Harris, 1999; Fahrenfort et al., 2009) as 
Table 4. Pharmacology to test the GABAergic feedback hypothesis

\begin{tabular}{|c|c|c|c|c|}
\hline & Number of mice/slices/cells & Control & Drug & Wash \\
\hline \multicolumn{5}{|l|}{ GABA, puff application } \\
\hline \multicolumn{5}{|c|}{ Bright responses ( $95 \%$ contrast) } \\
\hline Normalized $R_{\text {base }}$ & $1 / 2 / 19$ & 1.0 & $1.039 \pm 0.008^{* * *}$ & $1.051 \pm 0.017^{*}$ \\
\hline Normalized $R_{\mathrm{A}}$ & $1 / 2 / 19$ & 1.0 & $1.057 \pm 0.022^{*}$ & $0.978 \pm 0.030$ \\
\hline $\mathrm{PI}$ & $1 / 2 / 19$ & $0.045 \pm 0.006$ & $0.046 \pm 0.009$ & $0.048 \pm 0.006$ \\
\hline \multicolumn{5}{|c|}{ Dark responses ( $-39 \%$ contrast) } \\
\hline Normalized $R_{\text {base }}$ & $1 / 2 / 19$ & 1.0 & $1.043 \pm 0.012^{* * *}$ & $1.017 \pm 0.015$ \\
\hline Normalized $R_{\mathrm{A}}$ & $1 / 2 / 19$ & 1.0 & $1.187 \pm 0.046^{* * *}$ & $0.967 \pm 0.046$ \\
\hline $\mathrm{PI}$ & $1 / 2 / 19$ & $0.110 \pm 0.022$ & $0.082 \pm 0.020$ & $0.123 \pm 0.025$ \\
\hline \multirow{2}{*}{\multicolumn{5}{|c|}{$\begin{array}{l}\mathrm{Gz}+\text { TPMPA, bath application } \\
\text { Bright responses ( } 95 \% \text { contrast) }\end{array}$}} \\
\hline & & & & \\
\hline Normalized $R_{\text {base }}$ & $2 / 4 / 19$ & 1.0 & $0.992 \pm 0.021$ & $0.974 \pm 0.029$ \\
\hline Normalized $R_{\mathrm{A}}$ & $2 / 4 / 19$ & 1.0 & $1.005 \pm 0.070$ & $0.908 \pm 0.057$ \\
\hline $\mathrm{PI} \quad \stackrel{n}{n}$ & $2 / 4 / 19$ & $0.040 \pm 0.008$ & $0.047 \pm 0.005$ & $0.053 \pm 0.007$ \\
\hline \multicolumn{5}{|c|}{ Dark responses ( $-39 \%$ contrast) } \\
\hline Normalized $R_{\text {base }}$ & $4 / 5 / 10$ & 1.0 & $1.013 \pm 0.016$ & $0.991 \pm 0.019$ \\
\hline Normalized $R_{\mathrm{A}}$ & $4 / 5 / 10$ & 1.0 & $0.933 \pm 0.086$ & $0.852 \pm 0.084$ \\
\hline $\mathrm{PI} \quad n$ & $4 / 5 / 10$ & $0.131 \pm 0.040$ & $0.090 \pm 0.044$ & $0.141 \pm 0.042$ \\
\hline
\end{tabular}

were used for bath application (20 mM), we also puff applied HEPES. Here, the effective HEPES concentration at the cells is at least four times lower (see Materials and Methods). In addition to HEPES, we also tested the $\mathrm{pH}$ buffer Tris that lacks the aforementioned aminosulfonate moiety. For both puff-applied HEPES and Tris, we confirmed the results yielded with bath-applied HEPES (Table 3), arguing against substantial inhibition of hemichannels by HEPES.

In summary, clamping $\mathrm{pH}$ had contrast-dependent effects on bright flash-evoked responses and affected the kinetics of dark flash-evoked responses. Clamping $\mathrm{pH}$ did not have consistent effects on $R_{\text {base }}$, in contrast to the drugs that affected hemichannel-mediated feedback, which consistently increased $R_{\text {base }}$.

GABAergic transmission indirectly modulates cone output In the OPL, GABA may be released by HCs, which are considered GABAergic in mice (Schubert et al., 2010; Deniz et al., 2011; Herrmann et al., 2011), and by interplexiform cells (Dedek et al., 2009). To study the effect of GABA on cone $\mathrm{Ca}^{2+}$ signals (Fig. $8 A$ ), we puffed GABA onto the OPL while presenting light flashes (Fig. $8 B, F$ ). Application of GABA led to a small but significant increase in $R_{\text {base }}$ (Fig. $8 C, G$; for statistics, see Table 4 ) and $R_{\mathrm{A}}$ (Fig. $8 D, H$ ) for both bright and dark flash responses; PI, however, was not changed (Fig. 8E,I). The increase in $R_{\text {base }}$ and $R_{\mathrm{A}}$ is in contrast to what is expected from the classical hypothesis of inhibitory GABAergic feedback mediated by GABA receptors expressed on photoreceptors (Wu, 1986). Nevertheless, in light of a recent study by Liu et al. (2013), our data suggest a more complex role for GABA in the outer mouse retina: GABA is unlikely acting directly at the cone terminal, but instead may modulate cone output by controlling other feedback mechanisms.

To determine which cell types in the outer mouse retina express ionotropic GABA receptors and, therefore, may receive GABAergic input, we used electron microscopy (Fig. 9A,B). In previous studies, the $\alpha 1$ subunit (but not $\alpha 2$ or $\alpha 3$ subunits) of the $\mathrm{GABA}_{\mathrm{A}}$ receptor (Haverkamp and Wässle, 2000) and $\rho$ subunits of $\mathrm{GABA}_{\mathrm{C}}$ receptors (Enz et al., 1996) were found to be present in the rodent OPL. Our electron microscopy data show that none of the examined mouse cone terminals $(n=73)$ expressed either of these GABA receptor subunits (Fig. 9A,B), but we detected GABA receptors on the dendrites of cells postsynaptic to cones (HCs and ON-cone bipolar cells), as expected from functional studies (Feigenspan and Weiler, 2004; Duebel et al., 2006). The lack of GABA receptors on cone terminals but their presence on HCs in the mouse is consistent with our functional data: it argues against a direct inhibitory GABAergic feedback pathway acting at the cone terminal and supports the hypothesis of GABA autoreception-mediated effects on HCs (Liu et al., 2013). It is noteworthy that the $\mathrm{GABA}_{\mathrm{A}}$ and $\mathrm{GABA}_{\mathrm{C}}$ receptor antagonists $\mathrm{Gz}$ and TPMPA, respectively, did not affect $R_{\mathrm{A}}$ and $R_{\text {base }}$ (Fig. $9 C-H$ ), which may point at a lack of endogenous GABA in the sliced retina.

Together, GABAergic transmission appears to contribute to modulating cone output in the mouse retina, however, rather through indirect action (possibly autoreception in $\mathrm{HCs}$ ) and not directly via ionotropic GABA receptors on cone terminals.

\section{Local and global pharmacological manipulation of HC activity affect cone $\mathrm{Ca}^{2+}$ levels differently}

All three feedback mechanisms from HCs to cones can be simultaneously affected by clamping the input of HCs via AMPA/ kainate-type glutamate receptors (Schubert et al., 2006; Ströh et al., 2013) either with antagonists (NBQX) or agonists (AMPA/ kainate). Hyperpolarization of HCs by bath application of NBQX strongly increased $R_{\text {base }}$ (Fig. $10 A-C$ ), whereas depolarizing HCs with AMPA/kainate tended to reduce $R_{\text {base }}$ (Fig. $10 D, E$ ). Both effects were consistent over the whole light stimulation range used. We then measured the effects of NBQX and AMPA/kainate on the bright flash-evoked cone $\mathrm{Ca}^{2+}$ responses and found the same effects on $R_{\text {base }}$ (Fig. 10F, G,I, J; for statistics, see Table 5) as with the intensity ramp protocol (Fig. $10 A-E$ ). In addition, although NBQX had no effect on $R_{\mathrm{A}}$ (Fig. $10 F, H$ ), AMPA/kainate decreased $R_{\mathrm{A}}$ (Fig. 10I,K).

The effects of blocking glutamatergic input to HCs (by bath application) appear to be in conflict with our surround stimulation data, where hyperpolarizing HCs (by presenting bright stimuli in the surround; Fig. 1) and depolarizing HCs (by presenting dark stimuli in the surround; Fig. 2) decreased and increased $R_{\text {base }}$, respectively. However, when we puffed AMPA/kainate onto the recorded cones, locally "bathing" a tissue area of $\sim 100$ $\mu \mathrm{m}$ in width, we found $R_{\text {base }}$ to increase, which is the opposite 

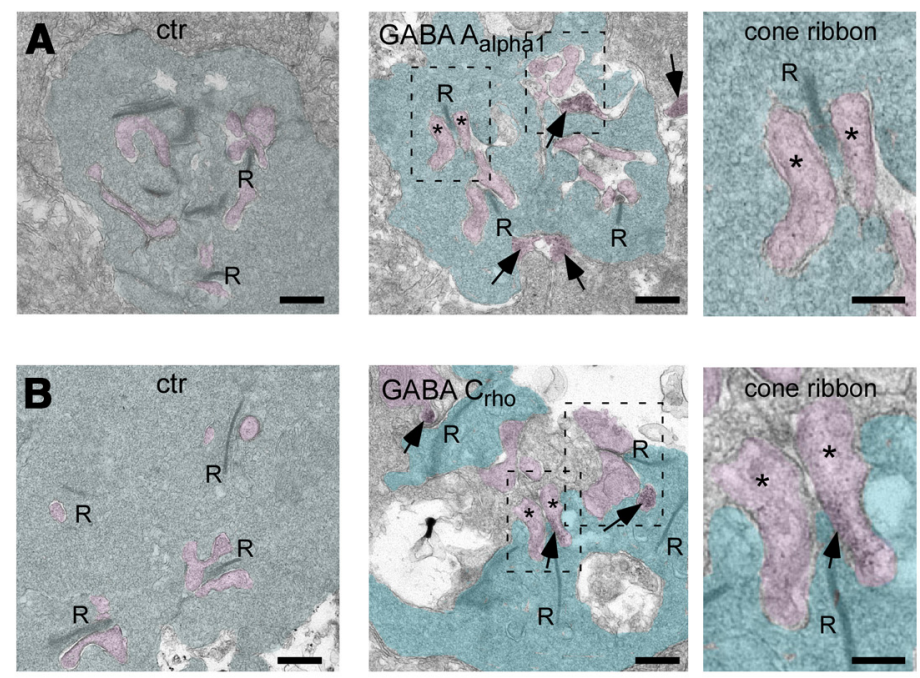

C

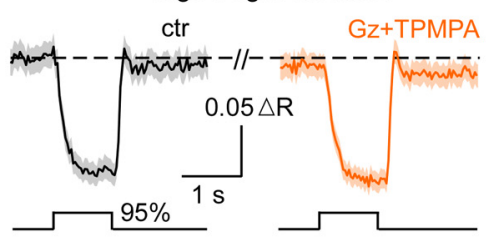

$\mathbf{F}$

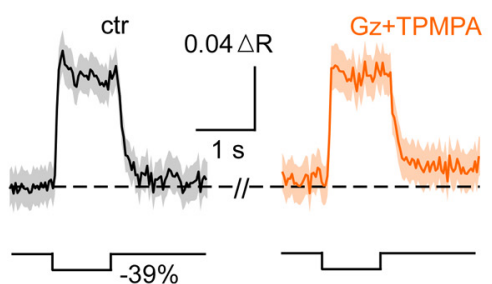

D

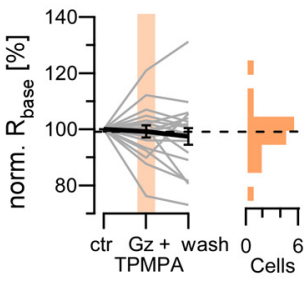

G

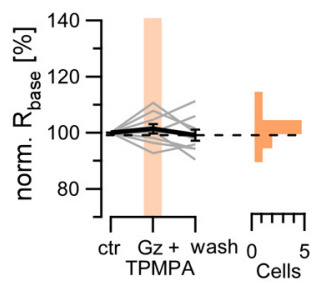

Figure 9. Cone axon terminals do not express ionotropic GABA receptors. $\boldsymbol{A}, \boldsymbol{B}$, Electron microscopy images showing immunolabeling for the $\alpha$ 1subunit of $\mathrm{GABA}_{\mathrm{A}}$ receptors $(\boldsymbol{A})$ and $\rho$ subunits of $\mathrm{GABA}_{C}$ receptors $(\boldsymbol{B})$ at cone ribbon synapses. Left, Immunolabeling without antibodies as control (ctr). Middle left, GABA receptor labeling. Middle right, magnified ribbon synapse region. Right, GABA receptors on ON-bipolar cell/HC dendrites (green, cone pedicle; purple, postsynaptic ON-bipolar cells/HCs; asterisks, $H C$ dendrites; arrows point at GABA receptor labeling on dendrites of postsynaptic cells; $R$, ribbon). Scale bars: left, $500 \mathrm{~nm}$; right, $200 \mathrm{~nm}$. C, F, Coapplication of the GABA receptor antagonists $\mathrm{Gz}$ and TPMPA did not affect cone $\mathrm{Ca}^{2+}$ responses to bright $(\boldsymbol{C} ; n=$ 19 cones averaged) $\operatorname{or}$ dark $\left(\boldsymbol{F} ; n=10\right.$ cones averaged) stimuli. $\boldsymbol{D}, \boldsymbol{E}, \boldsymbol{G}, \boldsymbol{H}$, Quantification of Gz+TPMPA effects on $R_{\text {base }}(\boldsymbol{D}, \boldsymbol{G})$ and $R_{\mathrm{A}}(\boldsymbol{E}, \boldsymbol{H})$ for the indicated stimulus protocols. Error bars indicate SEM. ctr, Control.

effect compared with (global) bath application (Fig. $10 L, M$ vs $I, J$ ) but consistent with the effect of presenting a dark stimulus in the surround (Fig. 2). The differential effects of local and global application are reminiscent of the findings by Jackman et al. (2011) in that HC feedback on cones appears to depend on the spatial scale of stimulation: local activation of HCs predominantly triggered (spatially restricted) positive feedback, whereas global HC activation strengthened the contribution of (laterally operating) negative feedback (see Discussion).

\section{Discussion}

Here, we present the first study that directly compares different HC feedback mechanisms in the mouse retina. We provide evidence that cone output is dominantly regulated by hemichannelmediated (putative ephaptic) and $\mathrm{pH}$-mediated feedback and that these two mechanisms modulate different aspects of the cone
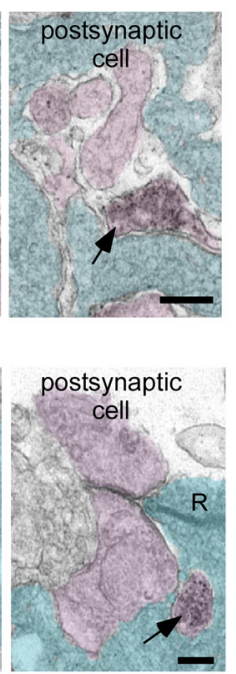

E

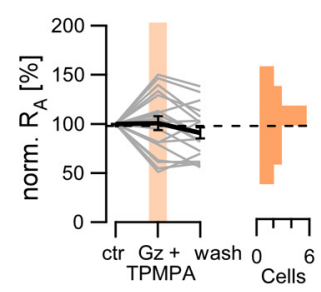

H

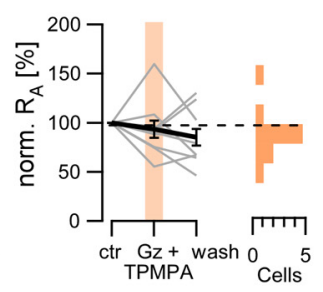

$\mathrm{Ca}^{2+}$ response. Hemichannel-mediated feedback modulates the cone resting $\mathrm{Ca}^{2+}$ level, the response size to bright flashes, as well as the response kinetics to dark flashes. In contrast, $\mathrm{pH}$-mediated feedback does not affect the cone resting $\mathrm{Ca}^{2+}$ level but modulates, as the putative ephaptic pathway, the response size to bright flashes and the response kinetics to dark flashes. GABA also modulates cone output, but the observed effect is inconsistent with direct GABAergic inhibition at cone terminals as proposed previously $(\mathrm{Wu}$, 1986). Instead, GABA appears to affect the other two feedback pathways, possibly via GABA autoreceptors on HCs (Liu et al., 2013).

\section{Is feedback from HCs to cones inhibitory or excitatory?}

Conceptually, HC feedback is thought of as inhibitory (Baylor et al., 1971). However, recently, evidence for excitatory HC feedback was presented (VanLeeuwen et al., 2009; Jackman et al., 2011). Like the classical inhibitory feedback, this excitatory feedback relies on glutamatergic transmission from cones to HCs, but it acts on a more local scale (Jackman et al., 2011). Jackman et al. (2011) proposed that such excitatory feedback could preserve signal strength by counteracting the degradational effects of the negative feedback. Here, we asked whether in the mouse retina both inhibitory and excitatory effects of HC feedback on cone $\mathrm{Ca}^{2+}$ signals could be observed. To this end, we first analyzed the effects of presenting bright or dark stimuli in a cone's $\mathrm{RF}$ surround on its $\mathrm{Ca}^{2+}$ responses: the cone $\mathrm{Ca}^{2+}$ responses were reduced by more light but increased by less light in the surround. From this we hypothesized that the effects of HC feedback are inhibitory for bright stimuli and excitatory for dark stimuli, in line with the earlier observations that (1) the effects of (inhibitory) HC feedback decrease substantially at more depolarized cone membrane potentials (Verweij et al., 1996) and (2) depolarizing HCs have excitatory effects on cone $\mathrm{Ca}^{2+}$ levels (Jackman et al., 2011).

In the second part, we aimed at dissecting the different hypothesized HC feedback mechanisms using full-field stimuli. We showed that drugs blocking hemichannel- and $\mathrm{pH}$-mediated feedback increased the size of cone $\mathrm{Ca}^{2+}$ responses to bright flashes, pointing at inhibitory effects of HC feedback for light presented to the surround, as expected from the surround-only stimulation experiments. For dark flashes, however, most of these drugs mainly affected the kinetics (PI) and had no effect on the size of cone $\mathrm{Ca}^{2+}$ responses. Thus, the excitatory effect of HC feedback on cone $\mathrm{Ca}^{2+}$ levels observed when presenting dark stimuli in a cone's surround may be mediated by a feedback mechanism that is little affected by the drugs used in this study. 
Notably, also Jackman et al. (2011) failed to unanimously identify the underlying mechanism of the positive feedback in their study. Nevertheless, our data confirm their finding that the excitatory HC feedback works on a more local scale: pharmacologically, we observed excitatory effects only when depolarizing HCs with local puff application of AMPA/kainate, but not with global bath application.

Hemichannel-mediated (ephaptic) and pH-mediated feedback regulate different aspects of cone synaptic output

Our pharmacological data suggest that both hemichannel-mediated (ephaptic) and $\mathrm{pH}$-mediated feedback are functional in the mouse retina. Blocking hemichannels/iGluRs and clamping $\mathrm{pH}$ in the synaptic cleft resulted in some common but also some substantially different effects on light-evoked cone $\mathrm{Ca}^{2+}$ signals. Together with previous studies (for review, see Thoreson and Mangel, 2012), our data indicate that both mechanisms may represent two sides of a complex feedback system that ensures reliable information transfer from cones to bipolar cells.

We propose that hemichannel-mediated (putative ephaptic) feedback is involved in controlling the cone terminal's resting $\mathrm{Ca}^{2+}$ as presenting light in a cone's $\mathrm{RF}$ surround reduced the $\mathrm{Ca}^{2+}$ level, an effect that was attenuated by hemichannel blockers. Also with full-field stimulation, blocking hemichannels increased the cone resting $\mathrm{Ca}^{2+}$ level. In contrast, blocking $\mathrm{pH}$-mediated feedback did not have consistent effects on the cone resting $\mathrm{Ca}^{2+}$ level. We think that the observed CBX effects on the cone $\mathrm{Ca}^{2+}$ level reflect modulation of putative ephaptic feedback, because (1) we could exclude other potential routes of CBX action, such as the disruption of the gap-junctionally coupled rod-cone network (Tsukamoto et al., 2001) or the direct or indirect modulation of iGluR-mediated currents; (2) different drugs targeting hemichannels or subtypes thereof (low cobalt, MFA, $\mathrm{PBC})$ had very similar effects as CBX; and (3) CBX increased $\mathrm{Ca}^{2+}$ levels, arguing against an unspecific inhibitory effect on VGCCs (Vessey et al., 2004). Moreover, CBX also increased the bright flash-evoked responses in cones, consistent with blocking inhibitory feedback (Kamermans et al., 2001). Functionally, hemichannel-mediated (ephaptic) feedback may be important for setting the gain of cone excitability, and thus keeping the cones responsive at different background light adaptation states.
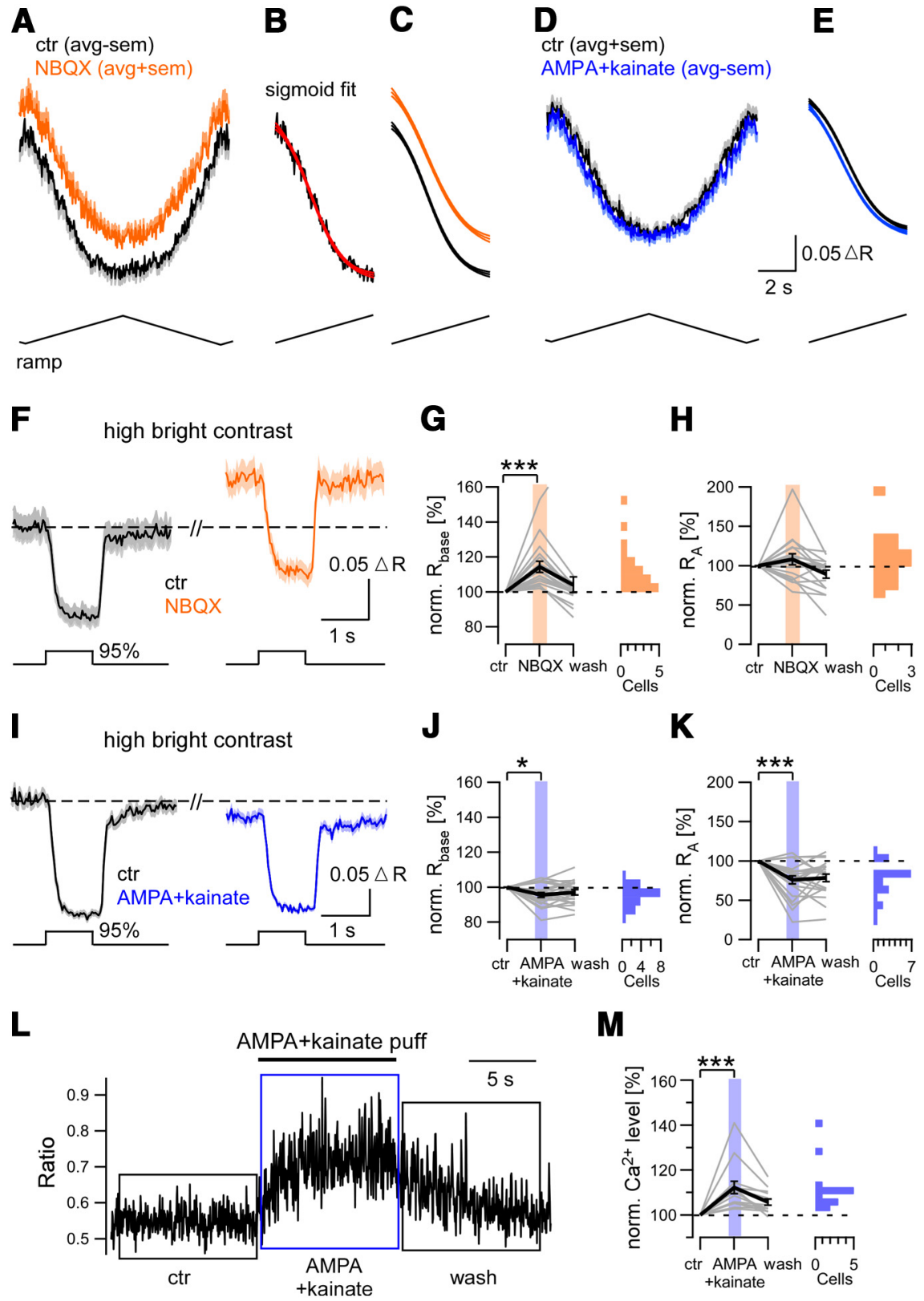

Figure 10. Clamping synaptic input to $\mathrm{HCs}$ modulates cone $\mathrm{Ca}^{2+}$ signals depending on the spatial scale of drug application. $A-C$, Effect of the AMPA/kainate-type GluR antagonist NBQX on cone $\mathrm{Ca}^{2+}$ level ( $n=12$ cones averaged) before (ctr, black) and during (orange) NBQX application while presenting an intensity ramp stimulus. The first part of the averaged response (black) fitted with a sigmoid (red; $\boldsymbol{B}$ ) and corresponding fits of control (ctr, black) and NBQX (orange) traces, with 95\% confident intervals (C). D, Effect of agonists AMPA/kainate on cone $\mathrm{Ca}^{2+}$ level $(n=21$ cones averaged) before (ctr, black) and during (blue) AMPA/kainate application while presenting an intensity ramp stimulus. $E$, Analyses analog to $B$ and $C$. $F$, Cone $\mathrm{Ca}^{2+}$ responses to the high bright contrast stimulus ( $n=18$ cones averaged) before (ctr, black) and during (orange) bath application of NBQX stimuli. $\boldsymbol{G}, \boldsymbol{H}$, Quantification of NBQX effect (bath application) on $R_{\text {base }}(\boldsymbol{G})$ and $R_{\mathrm{A}}(\boldsymbol{H}) . \boldsymbol{I}$, Cone $\mathrm{Ca}^{2+}$ responses to the high bright contrast stimulus ( $n=21$ cones averaged) before (ctr, black) and during (blue) bath application of AMPA/kainate. J, $\boldsymbol{K}$, Quantification of AMPA/kainate effect (bath application) on $R_{\text {base }}(J)$ and $R_{\mathrm{A}}(\boldsymbol{K})$. L, Puffing AMPA/kainate locally onto photoreceptor terminals increased cone $\mathrm{Ca}^{2+}$ level ( $n=14$ cones; boxes indicate time windows for calculating $\mathrm{Ca}^{2+}$ levels for control, AMPA/kainate, and washout conditions; no light flashes were applied, but the background light level was the same as for $\boldsymbol{I}$ ). $\boldsymbol{M}$, Quantification of AMPA/kainate effect (local puff) on cone $\mathrm{Ca}^{2+}$ level. Error bars indicate SEM.

In comparison, the effects of $\mathrm{pH}$-mediated feedback were much more diverse and strongly depended on the stimulus protocol: for instance, when high-contrast bright flashes were presented, the cone $\mathrm{Ca}^{2+}$ response increased in the presence of HEPES, pointing at "conventional" inhibitory $\mathrm{pH}$-mediated feedback, whereas with lower-contrast bright flashes, the cone 
Table 5. Pharmacology to manipulate the activity state of HCs

\begin{tabular}{|c|c|c|c|c|}
\hline & Number of mice/slices/cells & Control & Drug & Wash \\
\hline \multicolumn{5}{|l|}{ NBQX, bath application } \\
\hline \multicolumn{5}{|c|}{ Bright responses (95\% contrast) } \\
\hline Normalized $R_{\text {base }}$ & $2 / 5 / 18$ & 1.0 & $1.143 \pm 0.031^{* * *}$ & $1.039 \pm 0.047$ \\
\hline Normalized $R_{\mathrm{A}}$ & $2 / 5 / 18$ & 1.0 & $1.080 \pm 0.069$ & $0.892 \pm 0.050$ \\
\hline $\mathrm{Pl}$ & $2 / 5 / 18$ & $0.031 \pm 0.006$ & $0.043 \pm 0.008$ & $0.054 \pm 0.011$ \\
\hline \multicolumn{5}{|c|}{$\begin{array}{l}\text { AMPA + kainate, bath application } \\
\text { Bright responses ( } 95 \% \text { contrast) }\end{array}$} \\
\hline Normalized $R_{\text {base }}$ & $2 / 7 / 21$ & 1.0 & $0.955 \pm 0.014^{*}$ & $0.971 \pm 0.015$ \\
\hline Normalized $R_{\mathrm{A}}$ & $2 / 7 / 21$ & 1.0 & $0.758 \pm 0.052^{* * *}$ & $0.784 \pm 0.048^{* * *}$ \\
\hline $\mathrm{PI}$ & $2 / 7 / 21$ & $0.027 \pm 0.005$ & $0.027 \pm 0.005$ & $0.028 \pm 0.004$ \\
\hline
\end{tabular}

$R_{\text {base }}$ and $R_{\mathrm{A}}$ are normalized to 1 in the control condition. Results are presented as mean \pm SEM. Statistical significance is indicated as ${ }^{*} p<0.05,{ }^{* *} p<0.01$, and ${ }^{* * *} p<0.001$ [control vs drug or washout (Wash) conditions].

$\mathrm{Ca}^{2+}$ response decreased in the presence of HEPES, indicative of excitatory feedback. This suggests that $\mathrm{pH}$-mediated feedback results in a "compression" of the cones' response range to bright flashes: high contrasts attenuate, whereas low contrasts accentuate the responses. The $\mathrm{pH}$ of the synaptic cleft is controlled by a large number of $\mathrm{pH}$-regulating mechanisms, including $\mathrm{H}^{+}$- or $\mathrm{HCO}_{3}^{-}$-permeable channels and exchangers, the activity of which strongly depends on the HC membrane potential (for review, see Chesler, 2003). Therefore, depending on the stimulus contrast, one or the other $\mathrm{pH}$-regulating mechanisms may dominate, potentially resulting in net $\mathrm{pH}$ changes of different polarity for lower and higher contrast and leading to the respective (opposite) effects on the cone $\mathrm{Ca}^{2+}$ responses.

Together, we suggest that in the mouse retina, both hemichannel-mediated (ephaptic) and $\mathrm{pH}$-mediated feedback may act together and form a complex feedback system: (1) the putative ephaptic feedback sets the cone's output gain by adjusting the cone resting $\mathrm{Ca}^{2+}$ level, thereby adapting the cone output to the overall background light intensity; (2) the pH-mediated feedback compresses the cone output depending on the light stimulus contrast, possibly to maintain the cone response within its dynamic range; and (3) interestingly, both mechanisms appear to also affect the kinetics of the cones' dark response.

\section{What role does GABA play in the outer mouse retina?}

The first hypothesis forwarded about HC feedback involved a direct GABAergic pathway in the salamander retina (Wu, 1986): GABA released by HCs inhibits cones via GABA receptors on their pedicles. Over the years and, in particular, recently (Endeman et al., 2012; Liu et al., 2013), our view of the role of GABA in HC feedback became more differentiated. The data presented here confirm that GABAergic transmission plays a role in modulating cone output signals, but not via the classical pathway: no ionotropic GABA receptors were detected on cone terminals, and GABA receptor blockers did not affect the cone light response, arguing against a direct action of GABA at cone terminals. Yet, application of GABA resulted in larger cone light responses. How can this GABA effect be explained? One possibility is that GABA acts on HCs, which have been functionally shown to express $\mathrm{GABA}_{\mathrm{A}}$ receptors (Feigenspan and Weiler, 2004), thereby increasing the $\mathrm{HC}$ membrane conductance and shunting of the cation current flow through hemichannels (Endeman et al., 2012). This way, GABA would reduce ephaptic feedback, resulting in an elevated cone $\mathrm{Ca}^{2+}$ level and larger light-evoked $\mathrm{Ca}^{2+}$ signals, similar to what we observed in our CBX experiments. Alternatively, GABA-activating autoreceptors on HCs could also affect the pH-mediated feedback mechanism, as recently proposed by Liu et al. (2013): GABA receptors are permeable for both $\mathrm{Cl}^{-}$and bicarbonate (Bormann et al., 1987; Kaila et al.,
1993; Liu et al., 2013), and release of GABA by HCs and opening of GABA autoreceptors induces an outflow of bicarbonate from HCs into the synaptic cleft, when the membrane potential is more negative than the equilibrium potential for bicarbonate (at physiological pH usually $\sim 0 \mathrm{mV}$; Dallwig et al., 1999). Synaptic cleft alkalinization by bicarbonate increases the activity of cone VGCCs and disinhibits cones (Liu et al., 2013). Because the HC membrane potential is expected to be negative, it is therefore conceivable that GABA receptor activation increases VGCC activity via the aforementioned pathway. However, since direction and strength of the bicarbonate current critically depend on both the bicarbonate reversal potential and the HC's polarization state, it is difficult to ultimately ascribe our GABA findings to the pathway proposed by Liu et al. (2013) or, alternatively, to a shunting effect (Endeman et al., 2012).

Together, in the mouse retina, GABAergic transmission likely modulates hemichannel-mediated (ephaptic) and/or $\mathrm{pH}$-mediated feedback rather than providing direct feedback to cones.

\section{References}

Babai N, Thoreson WB (2009) Horizontal cell feedback regulates calcium currents and intracellular calcium levels in rod photoreceptors of salamander and mouse retina. J Physiol 587:2353-2364. CrossRef Medline

Baden T, Berens P, Bethge M, Euler T (2013a) Spikes in mammalian bipolar cells support temporal layering of the inner retina. Curr Biol 23:48-52. CrossRef Medline

Baden T, Schubert T, Chang L, Wei T, Zaichuk M, Wissinger B, Euler T (2013b) A tale of two retinal domains: near-optimal sampling of achromatic contrasts in natural scenes through asymmetric photoreceptor distribution. Neuron 80:1206-1217. CrossRef Medline

Bang S, Kim KY, Too S, Lee SH, Hwang SW (2007) Transient receptor potential V2 expressed in sensory neurons is activated by probenecid. Neurosci Lett 425:120-125. CrossRef Medline

Barnes S, Merchant V, Mahmud F (1993) Modulation of transmission gain by protons at the photoreceptor output synapse. Proc Natl Acad Sci U S A 90:10081-10085. CrossRef Medline

Baylor DA, Fuortes MG, O’Bryan PM (1971) Receptive fields of cones in the retina of the turtle. J Physiol 214:265-294. Medline

Bevans CG, Harris AL (1999) Regulation of connexin channels by pH. Direct action of the protonated form of taurine and other aminosulfonates. J Biol Chem 274:3711-3719. CrossRef Medline

Bormann J, Hamill OP, Sakmann B (1987) Mechanism of anion permeation through channels gated by glycine and gamma-aminobutyric acid in mouse cultured spinal neurones. J Physiol 385:243-286. Medline

Breuninger T, Puller C, Haverkamp S, Euler T (2011) Chromatic bipolar cell pathways in the mouse retina. J Neurosci 31:6504-6517. CrossRef Medline

Bruzzone R, Barbe MT, Jakob NJ, Monyer H (2005) Pharmacological properties of homomeric and heteromeric pannexin hemichannels expressed in Xenopus oocytes. J Neurochem 92:1033-1043. CrossRef Medline

Chang L, Breuninger T, Euler T (2013) Chromatic coding from cone-type unselective circuits in the mouse retina. Neuron 77:559-571. CrossRef Medline 
Chesler M (2003) Regulation and modulation of $\mathrm{pH}$ in the brain. Physiol Rev 83:1183-1221. Medline

Corey DP, Dubinsky JM, Schwartz EA (1984) The calcium current in inner segments of rods from the salamander (Ambystoma tigrinum) retina. J Physiol 354:557-575. Medline

Cueva JG, Haverkamp S, Reimer RJ, Edwards R, WässleH, Brecha NC (2002) Vesicular gamma-aminobutyric acid transporter expression in amacrine and horizontal cells. J Comp Neurol 445:227-237. CrossRef Medline

Dallwig R, Deitmer JW, Backus KH (1999) On the mechanism of GABAinduced currents in cultured rat cortical neurons. Pflugers Arch 437:289297. CrossRef Medline

Deans MR, Paul DL (2001) Mouse horizontal cells do not express connexin26 or connexin36. Cell Commun Adhes 8:361-366. CrossRef Medline

Dedek K, Breuninger T, de Sevilla MüllerLP, Maxeiner S, Schultz K, JanssenBienhold U, Willecke K, Euler T, Weiler R (2009) A novel type of interplexiform amacrine cell in the mouse retina. Eur J Neurosci 30:217-228. CrossRef Medline

Deniz S, Wersinger E, Schwab Y, Mura C, Erdelyi F, SzabóG, Rendon A, Sahel JA, Picaud S, Roux MJ (2011) Mammalian retinal horizontal cells are unconventional GABAergic neurons. J Neurochem 116:350-362. CrossRef Medline

Denk W, Strickler JH, Webb WW (1990) Two-photon laser scanning fluorescence microscopy. Science 248:73-76. CrossRef Medline

Duebel J, Haverkamp S, Schleich W, Feng G, Augustine GJ, Kuner T, Euler T (2006) Two-photon imaging reveals somatodendritic chloride gradient in retinal ON-type bipolar cells expressing the biosensor Clomeleon. Neuron 49:81-94. CrossRef Medline

Eggers ED, Lukasiewicz PD (2006) GABA(A), GABA(C) and glycine receptor-mediated inhibition differentially affects light-evoked signalling from mouse retinal rod bipolar cells. J Physiol 572:215-225. CrossRef Medline

Endeman D, Fahrenfort I, Sjoerdsma T, Steijaert M, Ten Eikelder H, Kamermans M (2012) Chloride currents in cones modify feedback from horizontal cells to cones in goldfish retina. J Physiol 590:5581-5595. CrossRef Medline

Enz R, BrandstätterJH, WässleH, Bormann J (1996) Immunocytochemical localization of the GABAc receptor rho subunits in the mammalian retina. J Neurosci 16:4479-4490. Medline

Euler T, Hausselt SE, Margolis DJ, Breuninger T, Castell X, Detwiler PB, Denk W (2009) Eyecup scope-optical recordings of light stimulus-evoked fluorescence signals in the retina. Pflugers Arch 457:1393-1414. CrossRef Medline

Fahrenfort I, Sjoerdsma T, Ripps H, Kamermans M (2004) Cobalt ions inhibit negative feedback in the outer retina by blocking hemichannels on horizontal cells. Vis Neurosci 21:501-511. CrossRef Medline

Fahrenfort I, Steijaert M, Sjoerdsma T, Vickers E, Ripps H, van Asselt J, Endeman D, Klooster J, Numan R, ten Eikelder H, von Gersdorff H, Kamermans M (2009) Hemichannel-mediated and pH-based feedback from horizontal cells to cones in the vertebrate retina. PLoS One 4:e6090. CrossRef Medline

Feigenspan A, Weiler R (2004) Electrophysiological properties of mouse horizontal cell GABAA receptors. J Neurophysiol 92:2789-2801. CrossRef Medline

Haverkamp S, Wässle H (2000) Immunocytochemical analysis of the mouse retina. J Comp Neurol 424:1-23. CrossRef Medline

Haverkamp S, Grünert U, WässleH (2000) The cone pedicle, a complex synapse in the retina. Neuron 27:85-95. CrossRef Medline

Herrmann R, Heflin SJ, Hammond T, Lee B, Wang J, Gainetdinov RR, Caron MG, Eggers ED, Frishman LJ, McCall MA, Arshavsky VY (2011) Rod vision is controlled by dopamine-dependent sensitization of rod bipolar cells by GABA. Neuron 72:101-110. CrossRef Medline

Hirano AA, BrandstätterJH, Morgans CW, Brecha NC (2011) SNAP25 expression in mammalian retinal horizontal cells. J Comp Neurol 519:972988. CrossRef Medline

Hirasawa H, Kaneko A (2003) pH changes in the invaginating synaptic cleft mediate feedback from horizontal cells to cone photoreceptors by modulating Ca2 + channels. J Gen Physiol 122:657-671. CrossRef Medline

Jackman SL, Choi SY, Thoreson WB, Rabl K, Bartoletti TM, Kramer RH (2009) Role of the synaptic ribbon in transmitting the cone light response. Nat Neurosci 12:303-310. CrossRef Medline

Jackman SL, Babai N, Chambers JJ, Thoreson WB, Kramer RH (2011) A positive feedback synapse from retinal horizontal cells to cone photoreceptors. PLoS Biol 9:e1001057. CrossRef Medline

Janssen-Bienhold U, Schultz K, Gellhaus A, Schmidt P, Ammermüller J, Weiler R (2001) Identification and localization of connexin26 within the photoreceptor-horizontal cell synaptic complex. Vis Neurosci 18: 169-178. CrossRef Medline

Janssen-Bienhold U, Trümpler J, Hilgen G, Schultz K, Müller LP, Sonntag S, Dedek K, Dirks P, Willecke K, Weiler R (2009) Connexin 57 is expressed in dendro-dendritic and axo-axonal gap junctions of mouse horizontal cells and its distribution is modulated by light. J Comp Neurol 513:363-374. CrossRef Medline

Jeon CJ, Strettoi E, Masland RH (1998) The major cell populations of the mouse retina. J Neurosci 18:8936-8946. Medline

Kaila K, Voipio J, Paalasmaa P, Pasternack M, Deisz RA (1993) The role of bicarbonate in GABAA receptor-mediated IPSPs of rat neocortical neurones. J Physiol 464:273-289. Medline

Kamermans M, Fahrenfort I (2004) Ephaptic interactions within a chemical synapse: hemichannel-mediated ephaptic inhibition in the retina. Curr Opin Neurobiol 14:531-541. CrossRef Medline

Kamermans M, Fahrenfort I, Schultz K, Janssen-Bienhold U, Sjoerdsma T, Weiler R (2001) Hemichannel-mediated inhibition in the outer retina. Science 292:1178-1180. CrossRef Medline

Kaneko A, Tachibana M (1986) Blocking effects of cobalt and related ions on the gamma-aminobutyric acid-induced current in turtle retinal cones. J Physiol 373:463-479. Medline

Klaassen LJ, Sun Z, Steijaert MN, Bolte P, Fahrenfort I, Sjoerdsma T, Klooster J, Claassen Y, Shields CR, Ten Eikelder HM, Janssen-Bienhold U, Zoidl G, McMahon DG, Kamermans M (2011) Synaptic transmission from horizontal cells to cones is impaired by loss of connexin hemichannels. PLoS Biol 9:e1001107. CrossRef Medline

Kraaij DA, Spekreijse H, Kamermans M (2000) The nature of surroundinduced depolarizing responses in goldfish cones. J Gen Physiol 115:3-16. CrossRef Medline

Kranz K, Dorgau B, Pottek M, Herrling R, Schultz K, Bolte P, Monyer H, Penuela S, Laird DW, Dedek K, Weiler R, Janssen-Bienhold U (2013) Expression of Pannexin1 in the outer plexiform layer of the mouse retina and physiological impact of its knockout. J Comp Neurol 521:1119-1135. CrossRef Medline

Li H, Zhang Z, Blackburn MR, Wang SW, Ribelayga CP, O'Brien J (2013) Adenosine and dopamine receptors coregulate photoreceptor coupling via gap junction phosphorylation in mouse retina. J Neurosci 33:31353150. CrossRef Medline

Liu X, Hirano AA, Sun X, Brecha NC, Barnes S (2013) Calcium channels in rat horizontal cells regulate feedback inhibition of photoreceptors through an unconventional GABA- and $\mathrm{pH}$-sensitive mechanism. J Physiol 591:3309-3324. CrossRef Medline

Mank M, Reiff DF, Heim N, Friedrich MW, Borst A, Griesbeck O (2006) A FRET-based calcium biosensor with fast signal kinetics and high fluorescence change. Biophys J 90:1790-1796. CrossRef Medline

Pan F, Mills SL, Massey SC (2007) Screening of gap junction antagonists on dye coupling in the rabbit retina. Vis Neurosci 24:609-618. CrossRef Medline

Peichl L, González-SorianoJ (1994) Morphological types of horizontal cell in rodent retinae: a comparison of rat, mouse, gerbil, and guinea pig. Vis Neurosci 11:501-517. CrossRef Medline

Prochnow N, Hoffmann S, Vroman R, Klooster J, Bunse S, Kamermans M, Dermietzel R, Zoidl G (2009) Pannexin1 in the outer retina of the zebrafish, Danio rerio. Neuroscience 162:1039-1054. CrossRef Medline

Schubert T, Weiler R, Feigenspan A (2006) Intracellular calcium is regulated by different pathways in horizontal cells of the mouse retina. J Neurophysiol 96:1278-1292. CrossRef Medline

Schubert T, Huckfeldt RM, Parker E, Campbell JE, Wong RO (2010) Assembly of the outer retina in the absence of GABA synthesis in horizontal cells. Neural Dev 5:15. CrossRef Medline

Shelley J, Dedek K, Schubert T, Feigenspan A, Schultz K, Hombach S, Willecke K, Weiler R (2006) Horizontal cell receptive fields are reduced in connexin57-deficient mice. Eur J Neurosci 23:3176-3186. CrossRef Medline

Shields CR, Klooster J, Claassen Y, Ul-Hussain M, Zoidl G, Dermietzel R, Kamermans M (2007) Retinal horizontal cell-specific promoter activity and protein expression of zebrafish connexin 52.6 and connexin 55.5. J Comp Neurol 501:765-779. CrossRef Medline 
Silverman W, Locovei S, Dahl G (2008) Probenecid, a gout remedy, inhibits pannexin 1 channels. Am J Physiol Cell Physiol 295:C761-C767. CrossRef Medline

Smith AJ, Oxley B, Malpas S, Pillai GV, Simpson PB (2004) Compounds exhibiting selective efficacy for different beta subunits of human recombinant gamma-aminobutyric acid A receptors. J Pharmacol Exp Ther 311:601-609. CrossRef Medline

Ströh S, Sonntag S, Janssen-Bienhold U, Schultz K, Cimiotti K, Weiler R, Willecke K, Dedek K (2013) Cell-specific cre recombinase expression allows selective ablation of glutamate receptors from mouse horizontal cells. PloS One 8:e83076. CrossRef Medline

Tatsukawa T, Hirasawa H, Kaneko A, Kaneda M (2005) GABA-mediated component in the feedback response of turtle retinal cones. Vis Neurosci 22:317-324. : CrossRef Medline

Thoreson WB (2007) Kinetics of synaptic transmission at ribbon synapses of rods and cones. Mol Neurobiol 36:205-223. CrossRef Medline

Thoreson WB, Burkhardt DA (1990) Effects of synaptic blocking agents on the depolarizing responses of turtle cones evoked by surround illumination. Vis Neurosci 5:571-583. CrossRef Medline

Thoreson WB, Mangel SC (2012) Lateral interactions in the outer retina. Prog Ret Eye Res 31:407-441. CrossRef Medline

Tovar KR, Maher BJ, Westbrook GL (2009) Direct actions of carbenoxolone on synaptic transmission and neuronal membrane properties. J Neurophysiol 102:974-978. CrossRef Medline

Tsukamoto Y, Morigiwa K, Ueda M, Sterling P (2001) Microcircuits for night vision in mouse retina. J Neurosci 21:8616-8623. Medline

VanLeeuwen M, Fahrenfort I, Sjoerdsma T, Numan R, Kamermans M (2009) Lateral gain control in the outer retina leads to potentiation of center responses of retinal neurons. J Neurosci 29:6358-6366. CrossRef Medline

Verweij J, Kamermans M, Spekreijse H (1996) Horizontal cells feed back to cones by shifting the cone calcium-current activation range. Vis Res 36 : 3943-3953. CrossRef Medline

Vessey JP, Lalonde MR, Mizan HA, Welch NC, Kelly ME, Barnes S (2004) Carbenoxolone inhibition of voltage-gated $\mathrm{Ca}$ channels and synaptic transmission in the retina. J Neurophysiol 92:1252-1256. CrossRef Medline

Vessey JP, Stratis AK, Daniels BA, Da Silva N, Jonz MG, Lalonde MR, Baldridge WH, Barnes S (2005) Proton-mediated feedback inhibition of presynaptic calcium channels at the cone photoreceptor synapse. J Neurosci 25:4108-4117. CrossRef Medline

Vigh J, Witkovsky P (1999) Sub-millimolar cobalt selectively inhibits the receptive field surround of retinal neurons. Vis Neurosci 16:159-168. CrossRef Medline

Voronin LL (2000) Intrasynaptic ephaptic feedback in central synapses. Neurosci Behav Physiol 30:575-585. CrossRef Medline

Vroman R, Klaassen LJ, Howlett MH, Cenedese V, Klooster J, Sjoerdsma T, Kamermans M (2014) Extracellular ATP hydrolysis inhibits synaptic transmission by increasing $\mathrm{pH}$ buffering in the synaptic cleft. PLoS Biol 12:e1001864. CrossRef Medline

Wei T, Schubert T, Paquet-Durand F, Tanimoto N, Chang L, Koeppen K, Ott T, Griesbeck O, Seeliger MW, Euler T, Wissinger B (2012) Light-driven calcium signals in mouse cone photoreceptors. J Neurosci 32:6981-6994. CrossRef Medline

Werblin FS (1978) Transmission along and between rods in the tiger salamander retina. J Physiol 280:449-470. Medline

Wu SM (1986) Effects of gamma-aminobutyric acid on cones and bipolar cells of the tiger salamander retina. Brain Res 365:70-77. CrossRef Medline

Xin D, Bloomfield SA (1999) Dark- and light-induced changes in coupling between horizontal cells in mammalian retina. J Comp Neurol 405:75-87. CrossRef Medline 